\title{
DE MONTÍCULOS A PAISAJES: PROCESOS DE TRANSFORMACIÓN Y CONSTRUCCIÓN DE PAISAJES EN EL SUR DE LA CUENCA DEL PLATA
}

\author{
FROM MOUNDS TO LANDSCAPES: THE TRANSFORMATION \\ PROCESSES AND THE CONSTRUCTION OF LANDSCAPES IN \\ SOUTHERN LA PLATA BASIN
}

\author{
Camila Gianotti ${ }^{1}$ y Mariano Bonomo ${ }^{2}$
}

\begin{abstract}
1. Centro Universitario de la Región Este, Laboratorio de Arqueología del Paisaje y Patrimonio (FHCE), unidad asociada a CURE, Universidad de la República, Uruguay. E-mail: camila.gianotti@lappu.edu.uy

2. CONICET - División Arqueología, Museo de La Plata, Facultad de Ciencias Naturales y Museo, Universidad Nacional de La Plata, Argentina. E-mail: mbonomo@fcnym.unlp.edu.ar
\end{abstract}

Presentado el: 24/07/2013 - Aceptado el: 25/10/2013

\section{Resumen}

A través de un estudio comparado, se analiza el rol que tuvo la construcción de montículos en la configuración de dos tipos particulares de paisajes arqueológicos: las estructuras monumentales (cerritos) de los humedales del noreste de Uruguay y los montículos antrópicos de las islas y ambientes litorales del Delta del río Paraná, Argentina. Sobre la base de los resultados de las prospecciones y excavaciones arqueológicas en estructuras monticulares de ambas regiones, se discute el origen de estas manifestaciones prehispánicas, los procesos de formación de sitio y las actividades implicadas, así como el desarrollo y conformación de estos paisajes arqueológicos. El análisis de las regularidades y las diferencias entre ambas experiencias regionales se integran en una discusión más amplia sobre la ocupación y trayectoria histórica de las tierras bajas sudamericanas.

Palabras claves: Paisajes arqueológicos; Cerritos; Delta del Paraná; Noreste de Uruguay; Tierras bajas sudamericanas.

\footnotetext{
Abstract

Through a comparative study, we analyze the role of mound building in the configuration of two particular types of archaeological landscapes: the monumental earthen structures (cerritos) of the wetlands of Northeast Uruguay and the human-made earthen mounds of the islands and littoral environments of the Delta of the Parana River, Argentina. Based on the results of archaeologica
} 
surveys and excavations of mound sites from both regions, the origin of these pre-Hispanic manifestations, the site formation processes and activities involved, and the development and shaping of these archaeological landscapes are discussed. The analysis of the regularities and differences between the two regional experiences are integrated into a broader discussion about the occupation and historical trajectory of Lowland South America.

Keywords: Archaeological landscapes; Mounds; Paraná Delta; Northeast of Uruguay; South American Lowlands

\section{Introducción}

A excepción del caso maya, las tierras bajas americanas tradicionalmente fueron vistas por la arqueología como ambientes homogéneos y adversos con bajo potencial económico que solo podían ser ocupados por pequeños grupos móviles con bajos niveles de desarrollo cultural que vivían dispersos en entornos prístinos. Sin embargo, este panorama ha cambiado en los últimos años, ya que en varios lugares de Amazonia se han encontrado diversas evidencias de complejidad social y política (Erickson 2006; Heckenberger y Neves 2009; Schaan 2012). Bajo la influencia teórica de la antropología amazónica, en las últimas décadas las tierras bajas sudamericanas reaparecen como espacios culturalmente construidos cuya profundidad histórica debe ser estudiada desde la arqueología a la hora de analizar su escenario ecológico actual. Los aportes hechos desde el marco conceptual de la ecología histórica han apuntado a desarrollar esta idea (entre otros Balée y Erickson 2006; Schaan 2012).

El interés en los estudios contemporáneos, y de este artículo en particular, se centra en analizar cómo se originan y construyen estos paisajes; por qué y a partir de qué tipo de relaciones sociales y qué prácticas acumuladas sobre el terreno, grupos distintos llegaron a resultados comparables en diferentes rincones del continente. Por este motivo es necesario comenzar a integrar las regularidades y diferencias de estas experiencias regionales en una discusión más amplia sobre la ocupación y trayectoria histórica de las tierras bajas de América del Sur. Esto, a su vez, estimulará la intercomunicación y el diálogo entre los/as investigadores/as que trabajan en regiones habitadas por sociedades diversas que a lo largo del Holoceno compartieron problemas similares. En este trabajo se discute el rol que tuvo la construcción de montículos en la configuración del paisaje monumental de los humedales uruguayos y del paisaje arqueológico formado por los montículos antrópicos de las islas y ambientes litorales del Delta del río Paraná (Figura 1).

Los procesos de antropización de las tierras bajas sudamericanas por parte de las poblaciones prehispánicas aparecen como un campo de investigación fértil para los enfoques que sitúan al paisaje como objeto y objetivo de estudio. Estos procesos se advierten con diferentes magnitudes y escalas, que van desde las modificaciones sutiles del ambiente llevadas a cabo por cazadores-recolectores o sociedades igualitarias (Politis 2007; Posey 2002) hasta la construcción de obras que implicaron conocimientos específicos sobre ingeniería y arquitectura y que condujeron a crear auténticos paisajes culturales. Montículos, campos elevados y terraplenes para el cultivo, islas forestadas, canales, lagunas artificiales, zanjas y plataformas forman parte de una extendida tradición de transformación del medio mediante la movilización masiva de sedimentos. Se ha planteado que además algunos de estos trabajos en tierra (earthworks) son verdaderos geoglifos que tuvieron funciones ceremoniales (Schaan 2012). Las diversas estrategias de modificación de la textura de la superficie terrestre fue compartida por grupos de diferentes partes de Sudamérica (Bonomo et al. 2011a; Erickson 


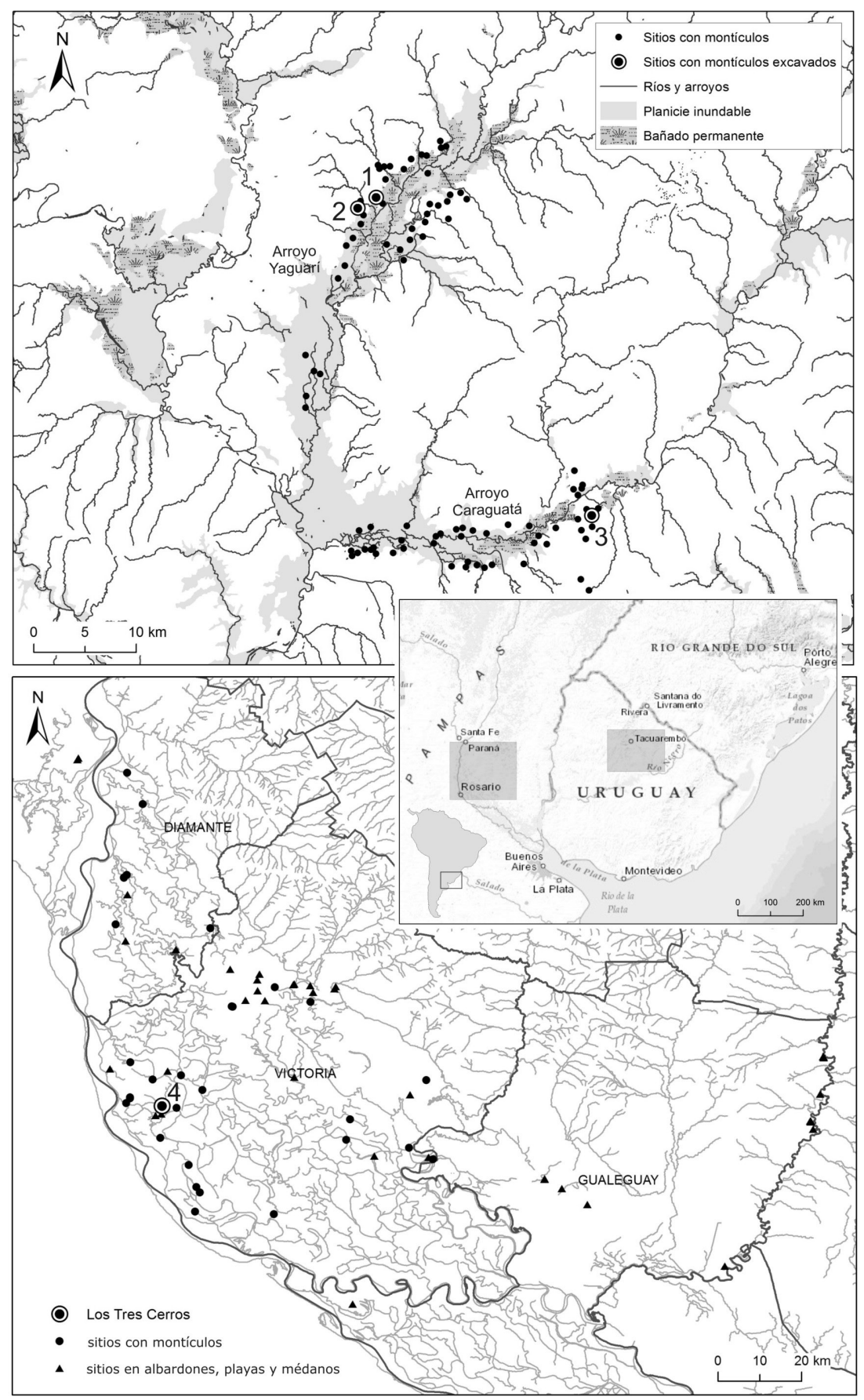

Figura 1. Localización de las áreas de estudio y los sitios con montículos analizados en el texto. 1) Sitio Lemos y 2) Cañada de los Caponcitos (Arroyo Yaguarí), 3) Sitio Pago Lindo (Arroyo Caraguatá), departamento de Tacuarembó; 4) Sitio Los Tres Cerros (departamento Victoria, Entre Ríos). 
2006, 2009; Iriarte 2006; López Mazz 2001; Lombardo y Prümers 2010; Politis et al. 2011; Rostain 2012a, 2012b; Walkers 2008), donde aún sobreviven estas estructuras después de siglos de erosión y alteraciones modernas tales como la introducción del ganado y la deforestación. El Pantanal del río Paraguay, las llanuras del Beni en Bolivia, los departamentos de Acre y Rondônia en Brasil, las tierras bajas de la Guayana francesa, el oriente y la costa ecuatoriana, el curso inferior de los ríos Paraná y Uruguay, los humedales del este y noreste de Uruguay, el Delta del Amazonas, entre otras regiones, albergan paisajes arqueológicos que testimonian complejos procesos de manejo del medio en los que la arquitectura en tierra funcionó como una auténtica tecnología socio-espacial que transcendió la variabilidad local y las fronteras etnolingüísticas.

Cada una de estas experiencias constituyen procesos adaptativos e históricos de manejo particular de ambientes húmedos que han dado lugar a niveles de complejidad social variables y fluctuantes durante el Holoceno medio y tardío (Barreto 2006). Si bien vienen siendo estudiados diferentes aspectos de todas estas transformaciones (e.g. Bracco et al. 2000; Iriarte 2006; Wüst y Barreto 1999), el rol de la arquitectura en tierra como dispositivo social de transformación permanente del espacio y elemento clave en la construcción de paisajes no ha sido abordado en profundidad, salvo en algunos trabajos en los que se reconocen procesos de domesticación (Erickson 2006) o de ceremonialización del paisaje (Schaan 2012), o asociados a su monumentalización (Gianotti 2005; López Mazz 1998; Suárez 2006).

\section{El paisaje en la arqueología}

El concepto de paisaje ha sido introducido en la investigación arqueológica de forma sistemática a partir de la década de 1980. Desde ahí en adelante se ha incrementado su campo de aplicación. Ha tenido un continuo desarrollo a lo largo de estos treinta años, lo cual condujo a que en la actualidad se lo reconozca como una perspectiva teórica específica. Aun cuando ésta se conoce como Arqueología del Paisaje, lo cierto es que engloba distintas visiones de los paisajes arqueológicos (David y Thomas 2010).

Desde los primeros estudios en el siglo XX que definen una tradición inglesa de los paisajes históricos, a los aportes de la geografía humanista y cultural norteamericana de la mano de C. Sauer y J. Brinckerhoff Jackson hasta su introducción en la arqueología, la noción de paisaje ha consolidado dos formas principales de conceptualizarlo. Una humanista, de carácter particularista, interesada en el genius loci, y más implicada con las preocupaciones de la historia. La otra, con un enfoque comparativo, teórico, interesado en los procesos culturales y con estrechos vínculos con la antropología (Johnson 2008).

Concretamente, en arqueología, el concepto paisaje llega con un carácter polisémico donde cada perspectiva (funcionalista, economicista, estructuralista, materialista o simbólica) le imprime cierta especificidad que ha derivado actualmente en la existencia de distintas arqueologías del paisaje (véase revisión en David y Thomas 2010). En algunas aproximaciones, el paisaje ha sido utilizado como sinónimo de ambiente (Rossignol y Wandsnider 1992), como espacio percibido, o sea desde una posición fenomenológica (Daniels y Cosgrove 1988; Thomas 2002), como construcción socio-simbólica (Criado Boado 1993), como territorio y formas materiales producidas por el trabajo humano y como lugar vivido (Ingold 1995; Tuan 2007), entre otras. 
A pesar de su diversidad, la arqueología del paisaje ha sido frecuentemente incluida dentro de las corrientes postprocesuales, siendo objeto de críticas sobre todo por el énfasis fenomenológico de algunas de las propuestas (Fleming 2006). Esto ha sido, sobre todo, por la reformulación crítica del concepto de espacio manejado hasta el momento por las arqueologías funcionalistas y ecologicistas, y por la proposición del paisaje como una categoría interpretativa no equiparable a la de medio natural externo, desacralizado y tangible. Más allá de la fenomenología de Tilley (1994) y Edmonds (1999), la relevancia de estas corrientes, agrupadas todas como postprocesuales, radica en la ruptura con las anteriores formas de aproximarse a lo espacial (Soler Segura 2007) y en transformar al paisaje en una matriz teórica que introduce aspectos no contemplados previamente. El espacio, cobra sentido como lugar al ser producido por la experiencia humana y por la acción social de carácter material e imaginario, tanto a nivel individual como colectivo (Criado Boado 1993).

El concepto de lugar adquiere un rol protagónico junto al paisaje para dar cuenta de los diferentes procesos implicados en la materialización de las prácticas sociales, y para integrar como elementos indisociables de éstas, las concepciones del mundo y las formas de representación de la realidad de las sociedades implicadas. Con la introducción del lugar, el espacio se llena de sentido, y es entonces cuando adquiere identidad y aparece vinculado a la experiencia y las prácticas sociales y simbólicas sobre un territorio (Alexiades 2009; Escobar 2001). Se pasa de la concepción universal y absoluta de espacio, al dominio de lo particular, lo local y limitado (Escobar 2001). Ambos conceptos (paisaje y lugar) se reivindican explícitamente escapando del vacío que proporciona el término de espacio, en el intento de humanizar la relación sociedad-entorno a través de la integración de otras perspectivas (Godelier 1989; Ingold 1995; Escobar 2001). Las perspectivas surgidas de estos procesos teóricos han sido agrupadas en dos principales, la del construir (building perspectives) y las perspectivas del habitar (dwelling perspectives) (Ingold 1995).

En la arqueología latinoamericana el análisis de los paisajes arqueológicos ha ganado fuerza en los últimos 15 años. Se empiezan a definir ciertas trayectorias propias del Sur (e.g. Curtoni 2007, Piazzini 2006; Troncoso 2008), y se producen nuevos aportes que integran enfoques teóricos de contextos académicos anglosajones e ibéricos (López Mazz 1998; Gianotti 2005; Mazzia 2011). La espacialidad del arte rupestre en todas sus escalas (Carden 2009; Troncoso 2008), el rol social y simbólico de los caminos (Curtoni 2007), la construcción de montículos (Bonomo et al. 2011a; Gianotti et al 2008; López Mazz 1998) y de concheros (de Blasi et al. 2007), las obras hidráulicas, los campos de cultivo y la arquitectura en tierra (Erickson 2006, 2009; Rostain 2012a; Schaan 2012) son distintos ámbitos temáticos dónde se vienen estudiando los paisajes sudamericanos. En estos trabajos, el espacio ha sido tratado como algo más que una matriz física; aparece como una vía alternativa a las aproximaciones cartesianas desde la cual se busca recomponer la jerarquía ontológica de éste, y de las materialidades, en el pensamiento arqueológico; sobre todo porque ambos fueron tratados como soportes pasivos o bien como externalidades distantes de la vida social (Piazzini 2006). Esta representación histórica y disciplinar del espacio condujo a que la arqueología se situara, desde sus orígenes, entre tensiones aún activas. Por un lado, aparece como ciencia de la cultura material (sin que se hubiera generado una ontología de las materialidades) con base en una ontología del tiempo (que sí recibió gran atención) y que finalmente ha derivado en la supremacía de éste frente al pensamiento del espacio (Criado Boado 1991; Piazzini 2006). 
En cierta forma, los estudios sobre el paisaje en arqueología han buscado trascender las definiciones de registro arqueológico, integrando los elementos no físicos de éste y proponiendo una nueva conceptualización más holística y relacional (Soler Segura 2007). Estas miradas en su conjunto suponen aportes relevantes a la interpretación del registro, pero ninguna se puede decir que constituya, en forma concreta, lo que se ha dado en llamar arqueología del paisaje. Es esta indefinición la que quizás ha permitido el éxito aparente de este campo específico de la arqueología. Precisamente, esta zona difusa en la que se mueve ha traído problemas para asimilar y establecer con claridad el potencial analítico y heurístico del concepto de paisaje (David y Thomas 2010; Jonhson 2008; Ruíz et al. 1998).

De todo lo anterior se desprende que lo que hoy entendemos como investigación acerca del paisaje o los paisajes, es el resultado de la convergencia de distintas miradas sobre el espacio geográfico y la interacción entre éste y los seres humanos. La ventaja comparativa para Latinoamérica, en relación a otras arqueologías del paisaje del Viejo Mundo viene dada, en muchos casos, por la presencia viva de agentes y comunidades responsables de esas experiencias; lo que posibilita conocer y articular en el espacio y en el tiempo, identidades y símbolos con la materialidad natural y cultural. Es así que, el paisaje aparece también como categoría adecuada para gestionar lugares, sitios y bienes arqueológicos y los vínculos entre éstos y sociedades pasadas y presentes (Endere y Curtoni 2003). Por todas estas razones, Sudamérica ofrece un fecundo laboratorio de estudio de los paisajes arqueológicos que permite indagar cómo se han constituido las experiencias y concepciones de espacio-tiempo de las sociedades no occidentales.

\section{Caso uruguayo: paisaje monumental de las tierras bajas del noreste de Uruguay}

En torno al 5000 A.P. en el este, y en el 3200 A.P. en el noreste de Uruguay, aparecen los primeros montículos conocidos como cerritos de indios (Bracco 2006; Gianotti 2005; López Mazz 2001). Estas construcciones se distribuyen también en las planicies inundables del sur de Brasil (Copê 1985; Naue et al. 1971; Rüthschilling 1989; Schmitz 1976). El uso y la construcción de cerritos, con diferentes funcionalidades (espacios domésticos, cementerios, microrrelieves para el cultivo, entre otras) permaneció hasta la conquista europea (Bracco 2006; Iriarte 2006; Bracco et al. 2000; López Mazz 2001). Las sociedades constructoras de cerritos mantuvieron, a lo largo de milenios, una economía mixta basada en la articulación de la caza y pesca (Pintos 1999) junto a la recolección y al aporte de la horticultura, especialmente de maíz, zapallo y porotos (del Puerto 2003; Iriarte 2006).

Las investigaciones sobre cerritos se desarrollaron desde hace 30 años fundamentalmente en la región sureste de Uruguay (Bracco et al. 2000; Bracco 2006; Cabrera 2005; Iriarte 2006; López Mazz 2001; Pintos 2000), salvo contadas excepciones (Baeza et al. 1974; Cabrera y Marozzi 2001; Sans 1985). A partir de la década de 1990 comienzan los trabajos en el noreste de Uruguay (departamento de Tacuarembó), hasta ese momento una región escasamente estudiada (Gianotti y Leoz 2001; Gianotti 2005; Gianotti et al. 2008; Criado Boado et al. 2004). Estas investigaciones brindaron datos novedosos para entender el fenómeno en clave regional y una nueva perspectiva complementaria de los enfoques existentes.

Las tierras bajas de la región Noreste se localizan en el departamento de Tacuarembó y, en menor medida, en el departamento de Rivera. Estas se caracterizan por la presencia de humedales permanentes asociados a las planicies de inundación de los cursos Tacuarembó, Yaguarí, Caraguatá, Tacuarembó chico; todos ellos tributarios del río Negro medio por su 
margen derecha. Entre el año 2001 y el 2009 tuvieron lugar en la cuenca del arroyo Yaguarí y Caraguatá tres proyectos de investigación orientados al estudio del origen y desarrollo de los montículos y su rol en la configuración de los paisajes monumentales prehistóricos. El interés principal se centró en tres objetivos generales: a) la caracterización arqueológica de los cerritos de la región, b) el análisis del contexto socioeconómico que amparó el desarrollo durante más de tres milenios de esta manifestación arqueológica y c) el análisis de la espacialidad indígena a partir del estudio del paisaje monumental y el rol que tuvo la arquitectura en tierra en la organización del territorio desde una perspectiva de larga de duración.

Una aproximación integral a todos estos aspectos planteó la necesidad de un abordaje a tres escalas principales: la región (que comprende una superficie de $8185 \mathrm{~km}^{2}$ entre ambas cuencas fluviales: Yaguarí y Caraguatá), el sitio (definido como tal el conjunto de cerritos) y el cerrito como estructura arqueológica mínima. A escala regional (Figura 1), se realizaron trabajos de prospección extensivas mediante fotointerpretación de fotografías aéreas pancromáticas a escala 1:20.000 que permitieron localizar conjuntos de cerritos y realizar mapeos preliminares de estructuras monticulares dentro de ellos (Gianotti 2004). A partir de los mapas preliminares se desarrollaron prospecciones intensivas dirigidas a contrastar la información obtenida en la fotointerpretación y a georreferenciar con GPS con corrección diferencial, mediante punto central y contorno, cada una de las estructuras arqueológicas existentes. Esta etapa del trabajo permitió localizar hasta la fecha 1023 estructuras monticulares fundamentalmente asociadas a las planicies de inundación y agrupadas en 97 conjuntos, 43 de ellos ubicados en el arroyo Yaguarí y 54 en el Caraguatá (Gianotti 2004; Gianotti et al. 2008). Entre las estructuras localizadas se identificaron construcciones similares a las identificadas y definidas para otros sitios con montículos (Iriarte 2006; Gianotti 1999; López 2001): cerritos circulares y alargados, microrelieves, plataformas y terraplenes que unen montículos. Además de estos volúmenes en tierra aparecen formando parte de los sitios: áreas con pérdida antropogénica de suelo, reconocidas como zonas de préstamo y/o de uso intenso asociadas a los momentos de ocupación, así como pequeñas lagunas circulares y canales rectilíneos asociados a éstas últimas que vienen siendo objeto de estudios detallados para clarificar su génesis (antrópica o natural), así como sus posibles usos.

La distribución y emplazamiento de los sitios permitió identificar tres patrones de agregación. Por un lado, agrupamientos con una alta densidad de montículos de entre 50 y 80 cerritos por sitio (sitios Nandubay, Caldas, Castro y Paso de los Ladrones), sitios que albergan entre 15 a 30 cerritos y, por último, sitios con una baja densidad de montículos, entre 2 a 5 montículos. Los sitios con mayor densidad de cerritos se sitúan en lugares que presentan condiciones estratégicas para el establecimiento de asentamientos domésticos (1): proximidad a cursos de agua dulce y a recursos (bañados y monte ribereño), en zonas de control de paso y/o concentración de fauna, con visibilidad inmediata sobre estos elementos y en estrecha relación con vías de circulación y/o pasos sobre ríos y bañados. Los cerritos aislados o sitios con baja densidad de montículos presentan otras características locacionales predominantes: gran dominio visual a larga distancia, sobre las lomadas, las planicies de inundación y sobre las cuchillas que fueron y siguen siendo utilizadas como vías de circulación regional.

Entre los cerritos del área de estudio predominan (63\%) los montículos con plantas de morfología circular de 30 a $45 \mathrm{~m}$ de diámetro y alturas entre los 0,70 y los $3 \mathrm{~m}$. Un $37 \%$ de los montículos del área de estudio presentan plantas de morfología alargada que alcanzan en algún caso los 70 a $120 \mathrm{~m}$ de largo en su eje mayor y 25 a $35 \mathrm{~m}$ de ancho y llegan a alcanzar los $4,5 \mathrm{~m}$ de altura. 
La configuración espacial de los cerritos exhibe regularidades formales que permiten identificar pautas comunes en la organización del espacio. Hay una tendencia destacada en la orientación de los conjuntos NW-SE, que también coincide con la orientación preferente de los cerritos alargados dentro de los conjuntos y con la orientación general de las formas naturales del relieve (2); Figura 2). En este sentido, los cerritos parecen adaptarse totalmente y reafirmar la topografía local. Al interior de los sitios, las diferentes construcciones antrópicas (microrrelieves, plataformas, cerritos, terraplenes) crearon espacios formalizados circulares y alargados (espacios acotados definidos por su forma y función como plazas, Iriarte 2006; López Mazz y Gianotti 1998), con una organización dual y en ocasiones simétrica de pares de cerritos paralelos y enfrentados, que conviven con otras estructuras con posibles alteraciones antrópicas (pequeñas lagunas o estanques, canales rectilíneos asociados y zonas con pérdida antropogénica de suelo).
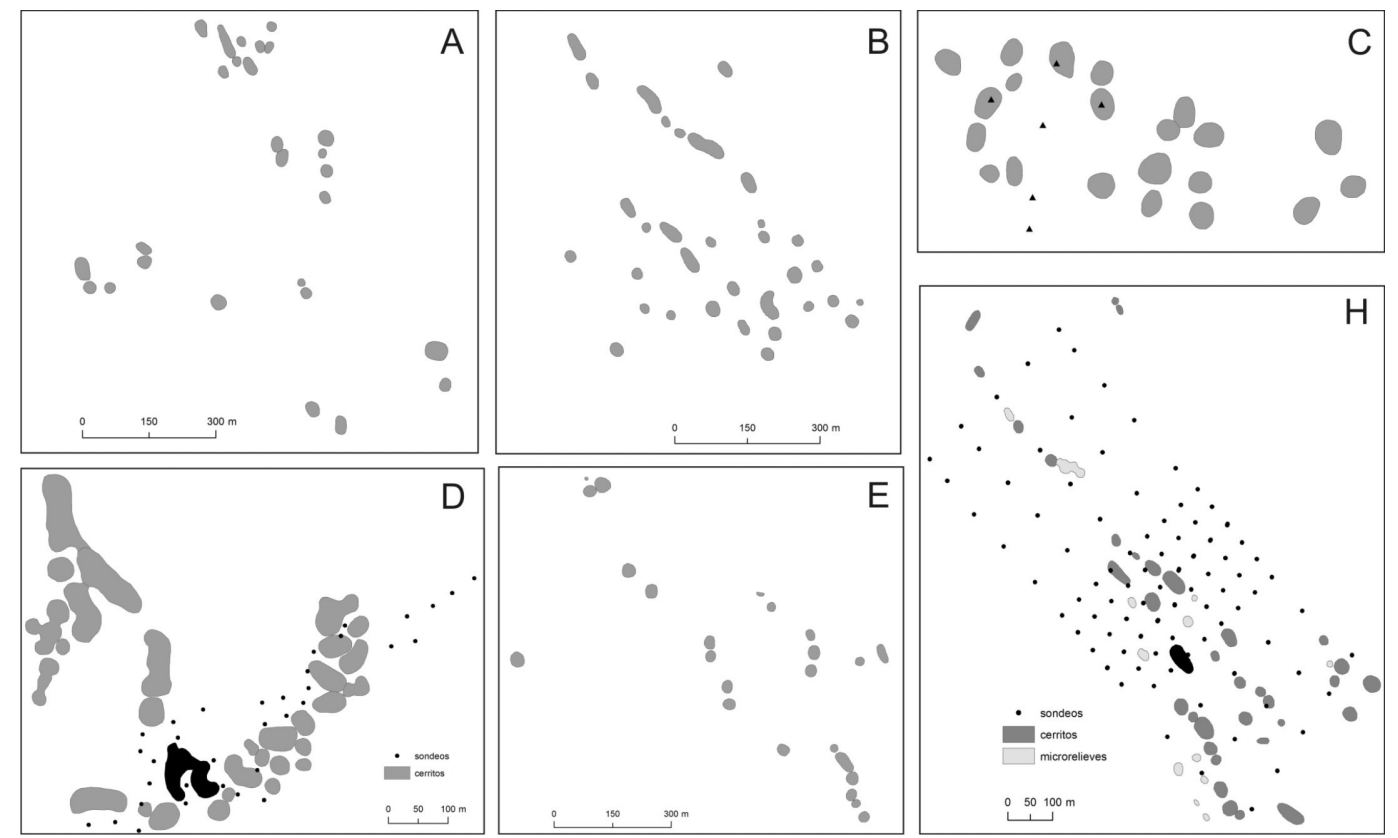

Figura 2. Distribución espacial al interior de sitios con montículos en la cuenca del Arroyo Yaguarí y Caraguatá. A) La Concesión; B) Echenagusía; C) Cañada de los Caponcitos; D) Pago Lindo; E) Ríos, F) Lemos. Se destaca en negro los cerritos excavados y sondeos realizados en $\mathrm{C}$, D y F.

Las distintas campañas arqueológicas realizadas en tres de los sitios del área durante los períodos 2001-2002, 2005-2006 y 2007-2010 permitieron caracterizar cronológica y funcionalmente algunos de los sitios monticulares de la región Noreste, aportando datos claves para definir patrones de asentamiento y para comprender el uso y configuración de territorios indígenas. Las intervenciones arqueológicas tuvieron lugar en los sitios Lemos y Cañada de los Caponcitos en el arroyo Yaguarí y en el sitio Pago Lindo en el arroyo Caraguatá. Los resultados de estos trabajos permitieron discutir sobre diferentes aspectos de los montículos del área, entre ellos: los procesos de formación de sitio y la dinámica constructiva de los montículos (Capdepont et al. 2005; Gianotti et al. 2009; Gianotti et al. e.p.; Suárez y Gianotti 2013), el manejo y cultivo de especies vegetales y su rol en la economía de estos grupos (del Puerto et al. 2005; del Puerto 2009; Gianotti et al. e.p.; Inda 2005), los 
aspectos centrales que caracterizan a la producción lítica (Blasco et al. 2011; López Mazz y Gascue 2005), la producción cerámica (Villarmarzo 2010), los principales cambios ambientales y la secuencia paleoclimática local (del Puerto et al. 2005; del Puerto 2010; Gianotti et al. e.p.).

A continuación presentamos una síntesis de los resultados obtenidos en dos de los sitios intervenidos.

\section{Sitio arqueológico Lemos}

El sitio Lemos se ubica en el extremo terminal de una de las dorsales de estribación de la Cuchilla de Yaguarí, rodeado por bañados permanentes y a escasos $500 \mathrm{~m}$ del arroyo homónimo. El conjunto presenta una extensión total de 1300 m (NW-SE) y 500 m (E-W). Se encuentra dividido en dos áreas (Lemos Norte y Lemos Sur) separadas por una pequeña cañada, afluente del $\mathrm{A}^{\circ}$ Yaguarí. En ambas áreas se localizaron durante las tareas de prospección un total de 52 montículos (14 alargados y 38 circulares), 11 microrrelieves y zonas con pérdida antropogénica de suelo, (Figura 1 y 2 f).

Durante el 2001 y 2002 se desarrollaron tres campañas en el sitio en las que se realizaron planimetrías de detalle con estación total, , una estrategia de cien sondeos estratigráficos sistemáticos en la planicie entre cerritos (de 0,50 x 0,50 m), seis sondeos en microrrelieves y se plantearon cuatro unidades de excavación, que totalizan 17,75 $\mathrm{m}^{2}$ en el cerrito 27 (de morfología alargada, $70 \mathrm{~m}$ por $21 \mathrm{~m}$ en planta y alturas de 1,10 $\mathrm{m}$ al norte y $0,80 \mathrm{~m}$ al sur). (Gianotti 2005).

En siete de los sondeos realizados en el sitio se registró material arqueológico (lítico y cerámica), cuatro de ellos en microrrelieves y tres en planicie entre cerritos. La ausencia de materiales en la planicie inmediata a los cerritos indica, o bien la inexistencia de áreas de actividad en el entorno de los mismos, o bien es indicativa de procesos de limpieza y remoción de sedimentos que borraron los restos de tales actividades. Esto contrasta con las evidencias registradas en conjuntos monticulares del sureste de Uruguay dónde se documenta la recurrencia de áreas de actividad en el entorno de los cerritos (Cabrera y Marozzi 2001; Curbelo et al. 1990; Iriarte 2006; López Mazz y Gianotti 1998).

Los resultados de las excavaciones en el cerrito 27 permitieron constatar que se trata de una estructura antrópica construida y utilizada en un lapso de 200 años, entre los 3250 y 3060 años AP. El incremento del volumen respondió a la superposición de dos eventos de construcción y ocupación del montículo, que se corresponden estratigráficamente con la UE01 y la UE02 (véase mayor detalle en Gianotti 2005). Ambas ocupaciones tuvieron un carácter fundamentalmente doméstico, evidenciado por el tipo de materiales recuperados, el reconocimiento de algunas actividades in situ (e.g. talla véase López Mazz y Gascue 2005) y por la presencia de estructuras domésticas al interior del cerrito: estructura de combustión, agujeros de poste y pequeñas estructuras lineales pertenecientes a algún tipo de construcción pequeña (Gianotti 2005).

La primera ocupación generó un volumen antrópico de escasa altura $(0,30 \mathrm{~m})$ que fue interpretado como el resultado de la acreción de desechos producidos por la actividad doméstica y caracterizado como un "monumento ambiguo" (Gianotti 2005). Dos siglos después, mediante un episodio constructivo intencional se remodeló el montículo anterior, acrecentándolo en altura y planta hasta configurar el cerrito tal como se encuentra 
actualmente. La naturaleza de este último episodio y de su depósito antrópico (UE002) fue el producto de un proceso de remodelación y de nueva construcción mediante el cual se monumentalizó el montículo preexistente.

Esta estructura en tierra fue construida con sedimentos procedentes de la remoción del horizonte A de la planicie circundante (Capdepont el al. 2005) y con distintos tipos de desechos producidos por la ocupación doméstica in situ (lítico, carbón, nódulos de tierra quemada, ocre, escasos fragmentos óseos y cerámica, presente solo en la segunda ocupación humana). En este evento de ocupación solamente se documentó una estructura arqueológica negativa en la esquina NW de la excavación, sin que se pudiera determinar su funcionalidad (Gianotti 2005). Los valores de pH en sedimentos del montículo (ácidos a débilmente ácidos desde el tope a la base) podrían haber afectado a la conservación de los restos óseos, de los que solo se han recuperado dientes de Myocastor coypus hacia la base del montículo. Esta situación es similar a la documentada en cerritos excavados en el sitio Pago Lindo (Caraguatá). Sin embargo, en otro cerrito excavado en 1983 (e.g. cerrito en sitio Caldas) se localizó un enterramiento primario hacia la mitad del perfil del cerrito (Sans 1985).

El análisis de partículas biosilíceas en sedimentos del cerrito proporcionó los primeros datos para la región que evidencian el aporte de los recursos vegetales a la economía prehispánica. Entre las especies silvestres documentadas se identificaron: hojas y rizoma de achira (Canna sp.), hojas de bromelias (Bromelia antiacantha), fruto de tala (Celtis tala), fruto de mburucuyá (Passiflora spp.), además de fitolitos atribuibles a ciperáceas y palmáceas. En cuanto a los vegetales manejados o cultivados, aparecen en la mitad superior del perfil y correspondiendo a la segunda y última ocupación y evento constructivo del montículo, fitolitos atribuibles a la cáscara del fruto de mate (Lagenaria siceraria) y a la hoja y chala del maíz (Zea mays) (del Puerto e Inda 2005).

Por otra parte, los resultados del análisis antracológico permitieron constatar la presencia de restos de Salix humboldtiana (sauce criollo) y Myrsine sp. (canelón) cuya presencia es habitual en el monte fluvial cercano. No obstante, la abundancia de restos de fabáceas (posiblemente de A. caven, espinillo) sugieren que el aprovisionamiento de combustible vegetal se hizo en las adyacencias del sitio (Inda 2005), en la llanura de inundación del Yaguarí donde actualmente se desarrollan extensos espinillares.

La cerámica recuperada está asociada únicamente a la segunda ocupación del cerrito (UE01) de la cual se obtuvo un fechado 14C sobre una muestra de carbón con una cronología de $3060+45 \mathrm{AP}, 68.3 \%$ - 1 sigma (Ua 21693; fecha calibrada 3240 - 3345 AP con $0.937 \%$ de probabilidad). Es una cerámica lisa, de factura simple, formas abiertas, cuyos rasgos tecnológicos son característicos de la cerámica conocida en la literatura brasileña como Viera (Brochado et al. 1969; Schmitz 1976). Entre los aspectos tecnológicos destacan el rodetado como técnica de manufactura, el alisado como terminación, y el uso de antiplástico de cuarzo molido y arena.

La producción lítica tallada se caracteriza por el aprovechamiento de recursos minerales disponibles en las cercanías del sitio (caliza silicificada, arenisca silicificada, calcedonia, xilópalo, cuarzo y cuarcita), presentes fundamentalmente en forma de rodados en el lecho de los ríos y arroyos cercanos. Las evidencias presentadas señalan la asociación de actividades de fabricación, uso, mantenimiento y descarte de artefactos líticos en el sitio. El ensamblaje de algunos fragmentos de lascas y de núcleo recuperados dentro de la UE02, generados 
por accidentes de talla, indica que los distintos procesos evidenciados e implicados en la fabricación de instrumentos líticos fueron realizados in situ. La presencia de percutores (fracturados y enteros) y de yunques en el conjunto, refuerza también esta hipótesis. No hay cambios tecnológicos marcados, ni cambios en las materias primas explotadas entre ambas ocupaciones (López Mazz y Gascue 2005).

Muy próximo al sitio Lemos (1350 m al SW), se ubica el sitio Cañada de los Caponcitos formado por 23 microrrelieves (Figura 2c). También allí se realizaron sondeos y análisis de sedimentos y partículas biosilíceas en tres microrrelieves y en la planicie circundante. Los resultados obtenidos mostraron, cómo los microrrelieves fueron construidos mediante la remoción del horizonte A del suelo circundante y, al menos, uno de ellos, fue utilizado para el cultivo de maíz ca. 800 años AP (Gianotti et al. e.p.). Estos datos, abren nuevas hipótesis acerca de la relación cronológica y funcional entre diferentes sitios de la cuenca del Yaguarí. Por otra parte, permite analizar los procesos de cambio inherentes al uso y construcción de montículos y cómo estos se manifiestan en la construcción social del paisaje.

\section{Sitio arqueológico Pago Lindo}

El sitio Pago Lindo se localiza en la margen izquierda del arroyo Caraguatá, sobre la planicie de inundación de una pequeña cañada afluente del mismo. Está formado por treinta y siete montículos antrópicos, dos lagunas circulares, un canal asociado a una de ellas y zonas con pérdida antropogénica de suelo en el entorno de los cerritos; todo ello en un área de aproximadamente $0,50 \mathrm{~km}^{2}$ (Figura 1 y 2d). Destaca por ser uno de los sitios con mayor densidad de montículos, que exhibe una organización espacial interna más compleja en relación a otros sitios próximos. Los cerritos se distribuyen a lo largo de una rinconada rodeada, hacia el norte, por la cañada y hacia el este y oeste, por bañado; mientras que hacia el sur se abre una extensa planicie que llega hasta el pie del cerro de las Crías, punto alto más cercano (128 msnm) desde donde se divisa y accede al sitio desde las zonas altas o cuchillas.

Entre los años 2005 y 2009 se desarrollaron cinco campañas en las que se realizaron prospecciones intensivas en las inmediaciones del sitio, planimetrías, 34 sondeos en la planicie entre cerritos, se plantearon doce sectores de excavación (cinco en estructuras arqueológicas no monticulares (dos lagunas y un canal asociado), cuatro sectores en uno de los montículos y tres fuera del mismo (Figura $2 \mathrm{~d}$ ). Además se realizaron análisis de materiales arqueológicos y análisis diversos sobre sedimentos (biosilíceos, físico-texturales y micromorfológicos).

El montículo excavado (PU061110Q23-25) es una estructura antrópica compleja en forma de $\mathrm{U}$, compuesta por la superposición y unión de varios montículos (circulares y alargados) de diferentes dimensiones. En planta, uno de los lados mide $63 \times 34 \mathrm{~m}$, mientras que otro lado mide $84 \times 37 \mathrm{~m}$. Las alturas oscilan entre los 2,80 m en su parte más alta y 0,60 m en la más baja. En total, el montículo tiene un volumen de $3783 \mathrm{~m}^{3}$. Se plantearon tres sectores de excavación; el sector 1 ubicado en una zona media, sobre un terraplén antrópico que parece unir dos montículos pre-existentes (Figura 5-H). Se trató de una excavación en área, con una superficie inicial de $16 \times 8 \mathrm{~m}$, que en una segunda campaña se redujo a $8 \times 4 \mathrm{~m}$. Por otro lado, sobre el lateral oeste se plantearon otros dos sectores de excavación de $2 \times 1 \mathrm{~m}$ (sector 4 y 5) en el centro de dos pequeños microrrelieves que forman parte del montículo. Las intervenciones se realizaron siguiendo metodología de excavación en área y por unidades estratigráficas con el objetivo de reconocer, por un lado, la dinámica constructiva y los procesos de formación de un montículo complejo; y por otro, estructuras visibles o latentes 
que permitan reconocer las actividades humanas asociadas al mismo. Los sectores 6, 7 y 11 $(0,50 \times 0,50 \mathrm{~m})$ son sondeos en el centro de lagunas circulares, el sector $3(6 \times 1 \mathrm{~m})$ se planteó en el canal asociado a una de ellas, mientras que los restantes sectores se abrieron con el objetivo de realizar control estratigráfico en diferentes zonas de la planicie. Los sondeos en lagunas y canal se plantearon con el objetivo de caracterizar la estratigrafía, sus cronologías y obtener datos que permitieran dilucidar la génesis natural o antrópica.

La actividad antrópica se concentró fundamentalmente en las estructuras monticulares. $\mathrm{Al}$ igual que sucede en el sitio Lemos ( $\mathrm{A}^{\circ}$ Yaguarí), la planicie inmediata a los cerritos no evidenció estructuras arqueológicas visibles, ni signos de ocupación intensiva. En solo 8 de los 34 sondeos realizados se documentó material arqueológico (desechos de talla y un fragmento cerámico). Por otra parte, los análisis estratigráficos en sondeos permitieron documentar remociones de sedimentos y zonas con pérdida antropogénica de suelo dentro del sitio, lo que también podría haber borrado evidencias de ocupación en la planicie.

En el montículo, los resultados de la excavación permitieron reconocer diferentes momentos concretos de actividad humana en el sitio Pago Lindo (Caraguatá) en un lapso temporal de ca. 2300 años; y que transcurre desde el 3000 AP hasta el 600 AP. La formación del terraplén que unió dos montículos preexistentes y de los microrrelieves que terminaron de configurar el volumen final del montículo complejo se produjo en nueve episodios de ocupación, entre los que se reconocieron dos eventos constructivos y otras actividades puntuales que tuvieron lugar en distintas zonas de los montículos preexistentes y el área periférica (Gianotti et al. 2009; Suárez y Gianotti 2013). Los distintos análisis realizados (sedimentos, micromorfología, partículas biosíliceas, cerámica, lítico y dataciones) permitieron caracterizar cronológica y funcionalmente algunos de estos episodios (Figuras 3 y 5). Los más destacados registrados en los sectores 1, 4 y 5 del montículo excavado se asocian a (ver fases en la matrix Harris, figura 3B):

1) actividad de talla (UE029) identificada a través de desechos y núcleos en el suelo previo a la formación del primer evento de construcción del montículo (episodio de ocupación pre-cerrito), en torno al $3000 \mathrm{AP}$;

2) ocupación doméstica sobre la planicie (entre dos cerritos preexistentes) en torno al 1600 AP. Durante esta fase se registraron actividades de limpieza, de remoción de tierra y preparación de una plataforma de 0,40 m y la construcción, encima de ella, de una estructura semicircular en materiales perecederos (UE005; UE030, entre otras). Agujeros de poste, pequeñas zanjas cerrando un espacio de $2,3 \mathrm{~m}$ de diámetro y conjuntos de piedra que aparecen como elementos interfaciales, lo confirman (Figura 4). Este episodio generó un volumen formado por la acreción producida tras el abandono y la posterior acumulación de desechos y sedimentos (Figura 3y 5);

3) un depósito de características físicas, texturales y micromorfológicas similares (UE022) se identificó al oeste del sector 1 . Si bien no se documentaron estructuras constructivas, ni ha sido fechado, se plantea a modo de hipótesis, una génesis similar al episodio anterior;

4) en torno al 1200 AP se produjo un nuevo episodio de ocupación doméstica y posterior abandono, al sur de uno de los cerritos pre-existentes (sector 5). Este episodio dio lugar a la formación de uno de los microrrelieves que terminó uniéndose al montículo, contribuyendo a definir la morfología compleja del mismo (Figura 3 y 5). En el sector 5 se documentaron 
dos estructuras de piedra, formadas por bloques de basalto agrupados (UE023 y UE024), que apoyan entre sí, y que aparecen asociados a pequeños agujeros de poste. Además se registraron diversos vestigios producto de la actividad doméstica (desechos de talla, cerámica, carbón) y la formación, por la acreción de desechos y sedimentos, de un depósito antrópico que configuró un microrrelieve (UE019);

5) otro episodio similar que dio como resultado la formación de un segundo microrrelieve, adosado al anterior, fue registrado en el sector 4 , pero aún no se ha datado.

6) en torno a los $900 \mathrm{AP}$ se registró un episodio constructivo intencional documentado en el área excavada. Se corresponde con la construcción del terraplén (UE003) que unió los dos cerritos pre-existentes y que proporcionó la morfología casi actual del montículo complejo. Este episodio estuvo asociado a una ocupación doméstica en el lugar, de la que se recuperaron numerosos vestigios: restos de talla, carbón, cerámica, semillas, y escasos fragmentos óseos.

7) Hacia ca. 800 AP se documentó un episodio constructivo y/o de uso en el montículo pre-existente, en el lado oeste. El depósito que generó este episodio también cubrió parcialmente el terraplén (construido alrededor de 100 años antes) que había unido los dos montículos pre-existentes (Este y Oeste) y derivó en el aumento del volumen del cerrito y también del terraplén.

8) En torno al 690 AP se produjo otra ocupación doméstica sobre el área del terraplén que generó un crecimiento leve del montículo producido por la acreción de desechos (UE002). En este depósito se recuperó la mayor parte del material cerámico, así como gran cantidad de desechos líticos, ocre y carbón.

En términos generales, la cerámica analizada (sector 1) se caracterizó como cerámica Viera. Apareció en todos los sectores, aunque la mayor frecuencia se asocia a la UE002, y en menor medida a las UE003, UE004-06 y UE019. Es una cerámica simple y utilitaria, de formas globulares y abiertas, con pastas compuestas por arcillas, arena y cuarzo machacado incorporado como antiplástico. Este gesto técnico también fue reconocido en el sitio Lemos (Yaguarí) y en otros cerritos excavados (López Mazz et al. 2001; Capdepont et al. 2002). El remontaje de varios tiestos, todos ellos dentro de la UE002, es un dato más que contribuye a la identificación de esta unidad estratigráfica como un paquete antropogénico producido por la actividad doméstica. Destaca la presencia de cerámica decorada $(n=4)$ siendo escasa o casi nula su presencia en el contexto de todos los cerritos excavados hasta el momento, en Rocha y Tacuarembó. Los motivos son impresos, en un caso unguiculada, en otro con un instrumento hueco de entre 1-2 mm de diámetro (hueso de ave) y el último aparenta ser impresión de cordel (Villarmarzo 2009).

El análisis del material lítico (Blasco et al. 2001), caracterizado fundamentalmente por desechos, núcleos y escasos instrumentos, es indicativo de actividad de talla intensa, orientada a la extracción de lascas para la elaboración de instrumentos y a la obtención de lascas para la utilización directa, desechando los núcleos una vez agotados. Predomina la materia prima de excelente calidad para la talla, tales como la caliza silicificada y la calcedonia, aunque se registra también el xilópalo, el cuarzo, la arenisca silificificada. Si bien están presentes todas las etapas de debitage, predominan las lascas primarias y secundarias frente a un bajo porcentaje de lascas corticales. Esto condujo a pensar que las primeras etapas 


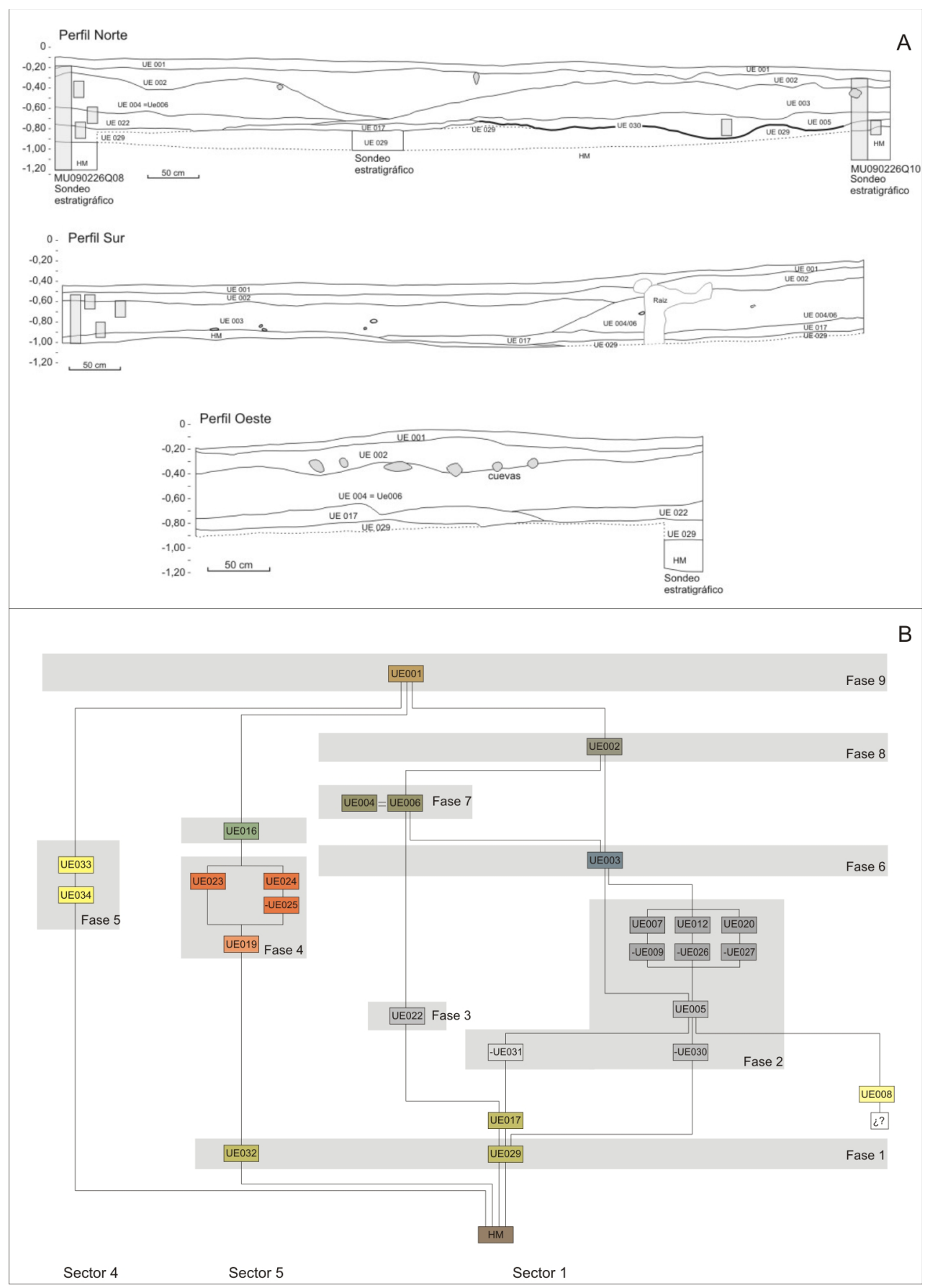

Figura 3. A) Estratigrafía de los perfiles Norte, Sur y Oeste del sector 1. B) Matrix Harris conjunta de todos los sectores excavados en el montículo. 


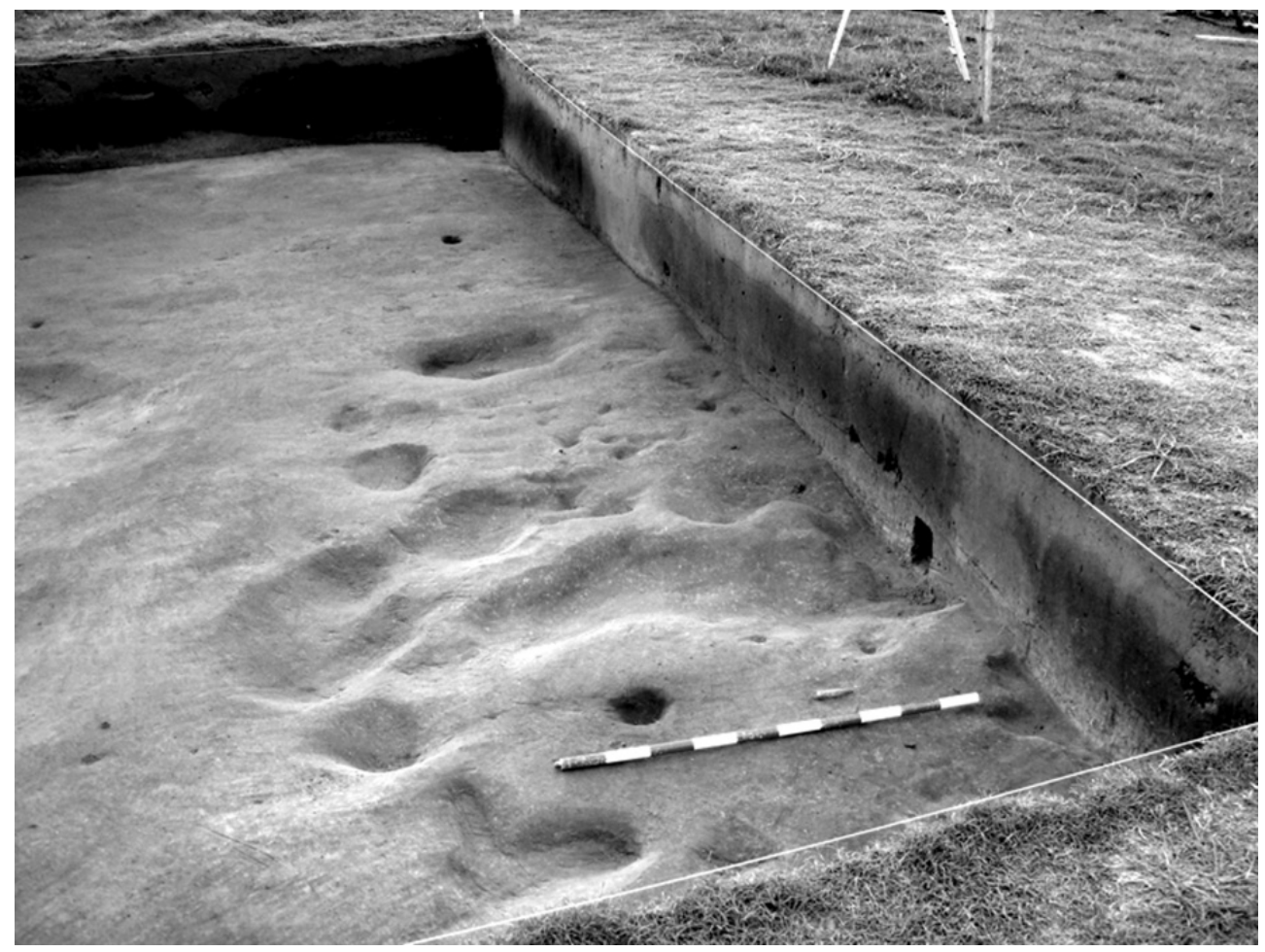

Figura 4. Vista parcial desde el SE de la planta de excavación con la estructura arqueológica registrada como UE030.

de descortezamiento se sucedieron fuera del montículo. La presencia de un alto porcentaje de rodados y clastos angulosos permitió interpretar que la mayor parte de la materia prima procede de fuentes de aprovisionamiento secundarias (salvo el xilópalo) ubicadas en el lecho de los cursos de agua próximos (Blasco et al. 2011).

También se recuperaron instrumentos pulimentados y fragmentos de éstos, entre los que se encuentran: instrumentos de molienda, manitos de moler, sobadores. Un aspecto destacado del conjunto lítico analizado, es el alto porcentaje de desechos, así como algunos instrumentos y núcleos, con claros indicios de alteración y/o daño térmico en sus superficies, lo que condujo a proponer que una buena parte de los desechos fueron tirados al fuego. Similares evidencias reportadas para el sitio Lemos, fueron interpretadas como parte de las actividades de mantenimiento y limpieza de desechos del área ocupada (López Mazz y Gascue 2005).

El análisis de partículas biosilíceas (del Puerto 2009) realizado sobre una columna de muestras tomada en el perfil Noreste del sector 1, permitió reconocer en la parte superior de la columna, asociado a la UE002 y UE003, la presencia de fitolitos de plantas silvestres como juncos, achira (Canna sp.), bromelias (Bromelia antiacantha), palmeras, algunas oryzáceas silvestres parientes del arroz, cuyo uso está documentado etnográficamente (del Puerto 2009). No obstante, la presencia de fitolitos de estas plantas no es necesariamente indicativa de su uso. Si bien se constató que la mayoría de los morfotipos involucrados aparece y/o incrementa su representación en los depósitos de origen antrópico, estos fitolitos pudieron ser transportados y depositados como parte del sedimento de construcción de la estructura. 
De la comparación entre el perfil del cerrito con perfiles del canal y la laguna colmatada surgió una mayor abundancia relativa de fitolitos de achira y bromelias en los depósitos antrópicos del cerrito, aunque estas diferencias no son extensibles a los otros potenciales recursos. Una situación mucho más clara apareció reflejada con la presencia de fitolitos atribuibles a recursos vegetales manejados y/o cultivados, como las cucurbitáceas y el maíz (Zea mays). Estos aparecieron en la zona superior de la secuencia sedimentaria, asociados a las UE002 y UE003. Su hallazgo constituye una nueva evidencia del manejo y cultivo de especies vegetales por parte de los grupos prehistóricos que ocuparon el área.

Por otra parte, los análisis de micromorfología de suelos y físico-texturales, mostraron, en términos generales, el uso recurrente de los horizontes superficiales como materia prima para la construcción del montículo. Se identificó la bioturbación como uno de los agentes más importantes de los procesos tafonómicos que podría estar causando el desplazamiento de artefactos macro y micro en los depósitos del montículo.

Las características físico-químicas y biológicas de los sedimentos enmascararon la preservación de límites claros entre las unidades estratigráficas interpretadas como los principales episodios de deposición. No obstante, esta situación y los procesos tafonómicos no eliminaron por completo la historia de la ocupación humana en Pago Lindo. Entre los rasgos reconocidos se encuentran evidencias de procesos de podsolización observados exclusivamente en una esquina de la zona del sector 1 (NE). Esto fue interpretado como el producto de la acumulación de desechos orgánicos sobre el montículo pre-existente en esta zona, hace 800 años.

Del mismo modo, los recubrimientos de arcilla identificados en el análisis micromorfológico del suelo debajo de la construcción con agujeros de poste (ca. 1600 años AP), han sido explicados por el intenso pisoteo humano producto de la ocupación doméstica en el lugar. Mientras que la ausencia casi total de restos micro-bioarqueológicos y la presencia de escasos fragmentos de carbón macroscópicos en el sitio, pueden ser interpretados como evidencia de la práctica de limpieza regular de las superficies de ocupación.

Por otra parte, se comprobó que las dos construcciones antrópicas excavadas, montículos y microrrelieves, muestran la misma composición sedimentaria.

En base a todos los resultados obtenidos durante las excavaciones y los análisis realizados se propuso un modelo de formación de montículos complejos que explica la génesis y crecimiento a partir de la ocupación humana de carácter doméstico (no se descartan otros posibles usos no reconocidos en estas excavaciones: e.g. funerarios), en distintos momentos y en diferentes sectores del espacio (Gianotti et al. 2009; Suárez y Gianotti 2013; Figura 4). Esta recurrencia de ocupaciones produciría el crecimiento progresivo de volúmenes en tierra, más o menos conspicuos, ya sea por deposición doméstica o por acumulación intencional, que se superponen totalmente en muchos casos, se solapan parcialmente en otros, o que incluso, no tienen contacto entre sí. Desde este modelo, los montículos en tierra son reconocidos, en ocasiones, como el resultado no-intencional de la vida doméstica, y en otras, como el producto intencional de episodios de construcción y/o remodelación de anteriores construcciones para originar una nueva. 


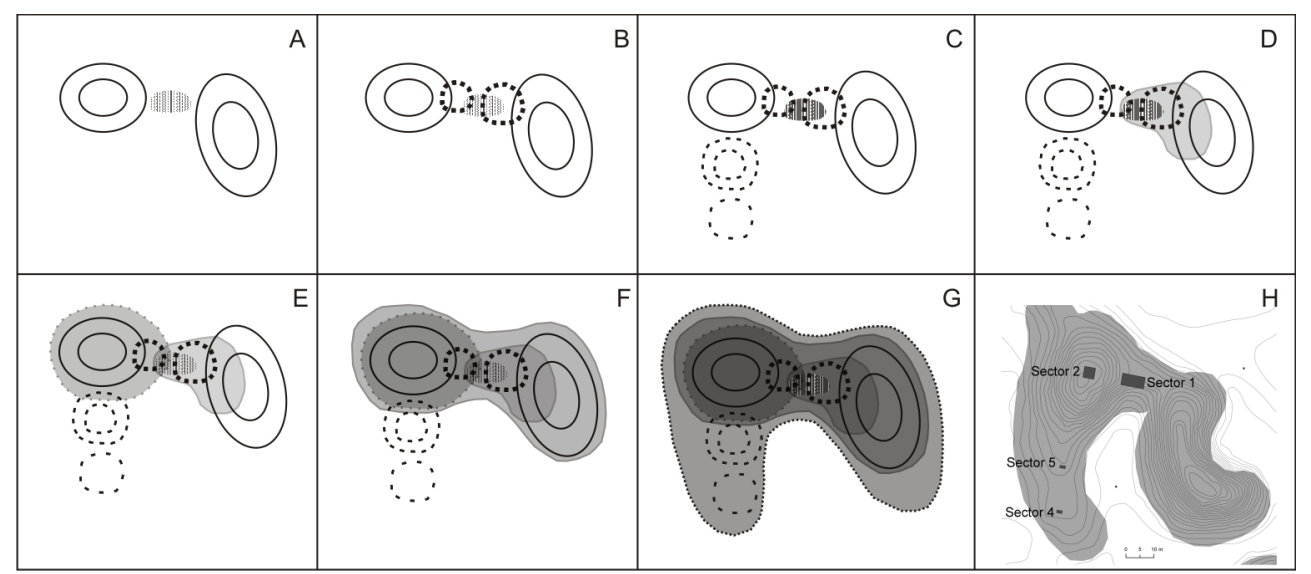

Figura 5. Modelo que sintetiza el proceso de formación del montículo excavado en el sitio Pago Lindo (Arroyo Caraguatá). En términos generales, A se corresponde con el episodio 1; B con el episodio 2 y 3 , C con el 4, D, 5, E con el 6, F con 7, G con el 8 y H representa la morfología actual del cerrito excavado en base a la planimetría de detalle.

\section{Caso argentino: los montículos prehispánicos del Delta del Paraná}

En el Delta del Paraná, al menos desde ca. 1000 a 490 AP, se han detectado las primeras evidencias claras de la construcción de montículos de tierra. Estas construcciones brindaron superficies estables para el asentamiento, mínimamente afectadas por las inundaciones, dentro de la dinámica llanura aluvial del Paraná. En este ambiente, sujeto a cambios periódicos en el nivel del río que desdibujan los límites entre las islas y el entorno acuático, las estructuras de tierra fueron erigidas para establecer áreas residenciales -que en algunos casos formaron aldeas- y para prácticas funerarias (Bonomo et al. 2011a; Ceruti y González 2007; Serrano 1950; Figura 1). Recientemente, también se ha planteado que algunos sectores de los montículos podrían haber sido utilizados como huertos (Sánchez et al. 2013). Estas estructuras se pueden agrupar de a dos o tres, pero por lo general están aisladas y separadas entre sí, mostrando un patrón de asentamiento predominantemente disperso. Esto no significa que se tratara de unidades aisladas y desconectadas; por el contrario parecen haber estado integradas en sistemas locales de interacción intragrupal y en redes suprarregionales de intercambio.

Las investigaciones geoarqueológicas recientes en los cerritos del Delta del Paraná permitieron proponer el carácter antrópico de las construcciones (Castiñeira et al. 2012; Politis et al. 2011). Estas construcciones fueron realizadas por poblaciones que habitaron este ambiente acuático, que practicaron una economía mixta y que han sido asociadas a la entidad arqueológica Goya-Malabrigo (Ceruti 1993, Politis y Bonomo 2012). La subsistencia estuvo basada en la caza de mamíferos (coipo, carpincho, cuis y cérvidos), la pesca (Characiformes y Siluriformes) y, en menor medida, se aprovecharon aves, reptiles y moluscos de agua dulce. Esta dieta era complementada con la recolección de frutos silvestres de algarrobo o de palmeras y mediante el cultivo, de tres especies ampliamente difundidas entre los trópicos americanos: el complejo maíz-poroto-zapallo (Bonomo et al. 2011a, 2011b; Sánchez et al. 2013).

En el curso inferior del río Uruguay también se ha identificado un patrón de asentamiento semejante, con montículos de formas circulares, ovales o elípticas. Los estudios de Castro (2012) en la margen izquierda del río Gualeguaychú ejemplifican esto. Allí, el Cerro Boari 3 (departamento Gualeguaychú, Entre Ríos) alcanza los $4 \mathrm{~m}$ de altura y fue sobreelevado 
intencionalmente sobre el terreno, aprovechando un albardón preexistente. Este sitio posee una potencia de más de 1,5 m de materiales arqueológicos: abundantes fragmentos de alfarería, artefactos líticos, restos óseos de mamíferos, peces y moluscos, instrumentos de hueso, vestigios de fogones y entierros humanos. A partir de restos óseos humanos y carbones recuperados en este montículo se obtuvieron cinco dataciones radiocarbónicas que abarcan el lapso comprendido entre los 1400 y 1000 años AP, mostrando evidencias más tempranas que las existentes por el momento para el Delta del Paraná.

\section{Sitio arqueológico Los Tres Cerros 1 (LTC1)}

La localidad arqueológica Los Tres Cerros (departamento Victoria, Entre Ríos; Figura 1) (Bonomo et al. 2010; Castiñeira et al. 2013; Politis et al. 2011) está localizada en la isla Las Moras, en la margen izquierda del zanjón Almada que corre paralelo al arroyo Paranacito. Está integrada por tres montículos de tierra en estrecha proximidad espacial que -luego de las crecidas del Paraná- quedan rodeados por un extenso bañado. Estos cerritos generalmente permanecen resguardados de las inundaciones y por ello favorecen el crecimiento de especies arbóreas como ceibos, sauces y timbós. Los materiales arqueológicos se distribuyen en los tres montículos, en la planicie adyacente y en tres microrrelieves próximos a los cerritos. En las sucesivas campañas realizadas en los años 2008, 2009, 2010, 2011 y 2012 se efectuaron decenas de sondeos estratigráficos de $0,5 \times 0,5 \mathrm{~m}$ y de $1 \times 1 \mathrm{~m}$, numerosos barrenos que alcanzaron profundidades mayores a los $3 \mathrm{~m}$, relevamientos planimétricos con Estación Total de los montículos y de sus capas constructivas y excavaciones que permitieron el desarrollo de estudios arqueológicos, geológicos y botánicos en esta localidad. Se excavaron $33 \mathrm{~m}^{2} \mathrm{en}$ la cima y la base de Los Tres Cerros 1 y $4 \mathrm{~m}^{2}$ en la cima de Los Tres Cerros 2. LTC1 (Figura 6) es el montículo central en relación con las otras dos elevaciones (separado por $133 \mathrm{~m}$ de LTC2 y por $106 \mathrm{~m}$ de LTC3) y sobresale del terreno llano circundante por ser la estructura de mayor altura. Allí, en las excavaciones se recuperaron abundantes tiestos cerámicos, restos faunísticos y entierros humanos.

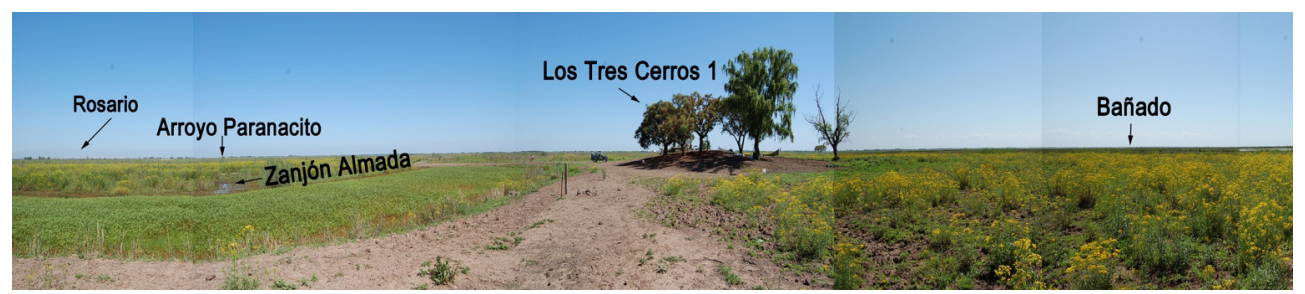

Figura 6. Vista panorámica del sitio arqueológico Los Tres Cerros 1

LTC1 es una elevación artificial que ha sido levantada más de dos metros por encima de la planicie mediante dos procesos: 1) con el agregado ad hoc de importantes cantidades de sedimentos sueltos y 2) con los restos descartados y abandonados durante los sucesivos eventos de ocupación. Los detallados estudios de Castiñeira et al. (2013) indican que la estructura monticular presenta acumulaciones antrópicas de sedimentos, tierras quemadas in situ y materiales arqueológicos. El montículo está conformado por diferentes niveles de acreción con un alto contenido de materia orgánica que contrasta con los suelos del área de escaso desarrollo y potencia. Se identificaron notables discrepancias texturales y mineralógicas entre los sedimentos naturales de la planicie adyacente en comparación con los del montículo; estos últimos fueron modificados por el fuego y por la incorporación 
de tiestos, carbón, valvas y huesos. Estos materiales de textura más gruesa habrían sido incluidos intencionalmente no solo para incrementar la altura del cerrito, sino también para consolidar los sedimentos finos y mantener la integridad de la estructura. El fuego seguramente también fue utilizado para consolidar y proteger la estructura de los agentes erosivos, para eliminar malezas y acondicionar el terreno y para endurecer posibles pisos de vivienda (Politis et al. 2013:fig. 8). Las diferencias composicionales entre los argilominerales de la estructura monticular y los horizontes naturales adyacentes apuntan a que el área de aporte para la acreción del montículo no se vincula con la remoción de sedimentos aluviales de la planicie circundante. Por el contrario, se privilegió la selección de fangos con propiedades cohesivas de áreas específicas que cumplían con las cualidades requeridas para la ingeniería constructiva (Castiñeira et al. 2013). El hallazgo de un bloque de tierra con un negativo de cestería en LTC1 (Figura 7) podría indicar el uso de canastas de carga para acarrear los sedimentos.
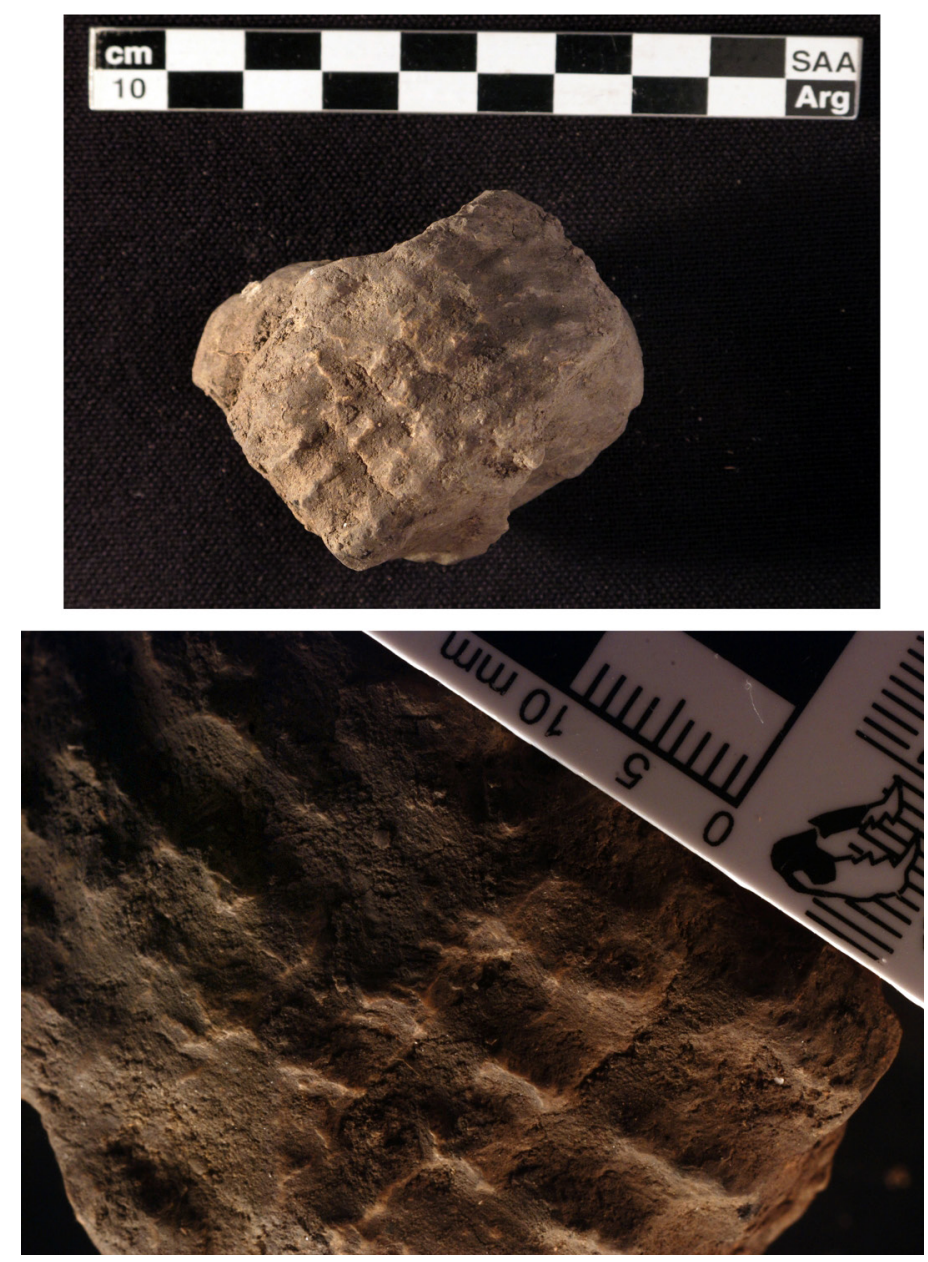

Figura 7. Bloque de sedimento con impronta de cestería hallado en LTC1 (arriba). Detalle de la impronta (abajo). 
La elevación de este montículo demandó el movimiento y la despositación de más de 1700 metros cúbicos de tierra, lo cual incluyó diferentes etapas de trabajo grupal distribuidas a lo largo de varios siglos. Las 19 dataciones radiocarbónicas obtenidas en LTC1 muestran que el sitio fue ocupado entre los 1200 y 560 años AP, con periodos prolongados de estabilidad alternados con episodios de abandono y posterior re-ocupación. A lo largo de este periodo, poblaciones dedicadas a la caza, la recolección, la pesca y la horticultura utilizaron el montículo para asentar sus viviendas, desarrollar actividades domésticas y enterrar a sus muertos (Politis et al. 2011). En la cima del cerro se evidencian estas actividades domésticas a partir del registro de fogones, pozos con abundantes restos de pescado, posibles marcas de poste (círculos de entre 5 y $11 \mathrm{~cm}$ de diámetro preservados en las tierras quemadas) y los mencionados pisos de vivienda. La cima estuvo sujeta a tareas de limpieza, hecho inferido por la menor densidad de desechos en comparación con el basurero detectado en la base del montículo y que posee una gran cantidad de tiestos y de huesos de animales fracturados, con huellas de corte y termoalteración. Esta concentración de materiales en la base del montículo también ha recibido aportes de materiales removidos y redepositados por agentes naturales.

La cronología, la ubicación geográfica y las características estilísticas y tecnológicas de la cerámica relacionan estas ocupaciones con la entidad arqueológica Goya-Malabrigo (Ceruti 1993; Politis y Bonomo 2012). La alfarería domina el conjunto artefactual del sitio con más de 30.000 tiestos (Di Prado y Castro 2013). La manufactura cerámica se realizó en el lugar, tal como lo indica la presencia de masas y rollos de arcilla y alisadores de cerámica. En LTC1 se abandonaron las características "campanas" (tres grandes y dos muy pequeñas), que son piezas con forma de cilindro o cono truncado, abierto en la parte inferior y con un apéndice zoomorfo en la superior. Además se halló una vasija con tres compartimentos en su interior, un tortero para hilar fibras, siluetas recortadas con formas de psitácidos (incluyen a los guacamayos, loros y cotorras) y modelados escultóricos macizos (Figura 8) que representan aves, mamíferos, reptiles y moluscos. Entre los apéndices zoomorfos se destacan las representaciones de cabezas de aves que poseen plumajes coloridos y brillantes (psitácidos) y de rapaces diurnas (falconiformes), así como de animales solitarios que son peligrosos para los humanos (e.g. ofidios). El surco rítmico fue la técnica decorativa predominante y se utilizó para trazar líneas rectas, escalonadas, zigzags y figuras geométricas. También hay fragmentos con superficies pintadas de rojo, un tiesto corrugado y otro unguiculado, provenientes ambos de las capas más superficiales del sitio.

Los artefactos líticos son muy escasos (25 registrados hasta el momento), y las materias primas proceden de distintas formaciones geológicas. La rocas utilizadas incluyen: areniscas de las formaciones Paraná e Ituzaingó, que afloran a más de 50 km de LTC1, en la margen izquierda del río Paraná y sus tributarios; calizas silicificadas de la Fm. Puerto Yeruá y basalto vesicular de la Fm. Serra Geral, disponibles en el río Uruguay y tributarios, a una distancia mayor a $230 \mathrm{~km}$. También se han abandonado distintas clases de artefactos óseos: puntas acanaladas, semi-acanaladas y planas con pedúnculo y sin éste, cabezales de arpón $\mathrm{y}$ un pendiente.

Se hallaron abundantes huesos y dientes correspondientes a coipo (Myocastor coypus) y a carpincho (Hidrochoerus hidrochaeris), roedores que constituyen las especies más representadas y en las que se identificaron fracturas y huellas producidas durante la desarticulación de las carcasas, la extracción del cuero y el consumo de su carne (Bastourre 2012). Otros recursos presentes son el cuis (Cavia aperea), el zorro pampeano (Lycalopex gimocercus), las almejas de 


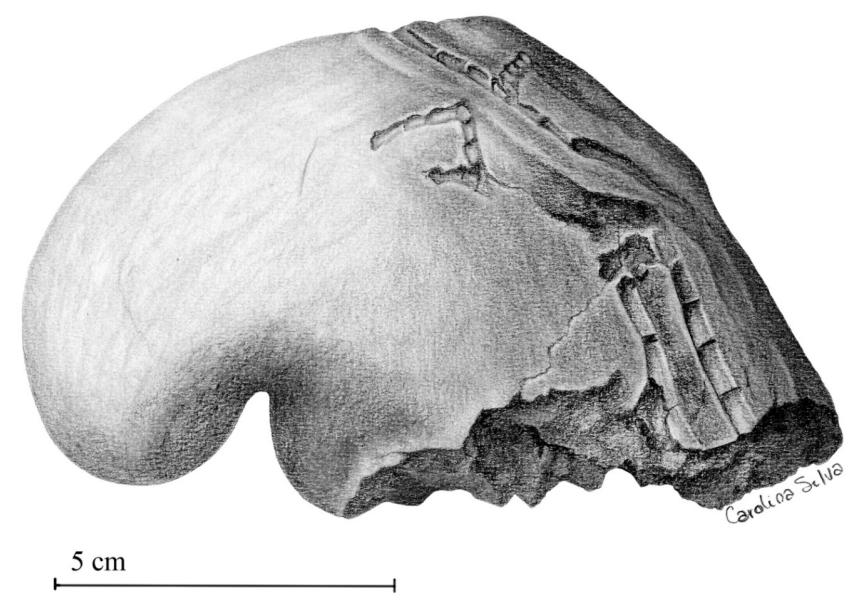

Figura 8. Apéndice zoomorfo que representa la cabeza de un loro recuperado en Los Tres Cerros 1 (dibujo de Carolina Silva).

agua dulce (Diplodon sp.) y en muy baja frecuencia ampuláridos. Además, se encontraron huesos del cráneo, espinas y vértebras de peces: tararira (Hoplias malabaricus), boga (Leporinus obtusidens), chanchita (Cichlasoma facetum) y armado común (Pterodoras granulosus).

Los estudios arqueobotánicos de Sánchez et al. (2013) identificaron fitolitos globulares de Palmáceas, con superficies con mamelones y/o corrugadas de Equisetum sp., de bordes facetados de Canna sp. (achira) y cruces de Orizeae (familia que incluye al arroz silvestre). A estas evidencias de manipulación de los vegetales disponibles en forma silvestre, se le agregan morfotipos en forma de cruz afines a Zea mays (maíz) y morfotipos cavados de cucurbitáceas. En el caso del maíz, además se lo registró con gran abundancia en el interior de tres grandes fragmentos de un recipiente cerámico (Sánchez et al. 2013). Esta especie fue detectada en las muestras sedimentarias tomadas a lo largo del perfil, incluso en las de los niveles inferiores (Milagros Colobig com. pers.) datados entre 970 y 1030 años AP. Estos resultados apoyan la presencia de un componente hortícola en la subsistencia de los ocupantes de LTC1, desde los inicios de la elevación del montículo.

Los análisis antracológicos desarrollados por Brea et al. (2013) identificaron elementos arbóreos de Acacia sp. (espinillo), Prosopis sp. (algarrobo), Ocotea sp. (laurel), Sapium sp. (curupí), Enterolobium sp. (timbó colorado), Erythrina sp. (ceibo) y Cordia sp. (petiribí). Esta información permitió conocer el combustible usado en los fogones del sitio donde se combinaron leñas duras y blandas, así como las maderas empleadas con otros fines que fueron seleccionadas de distintos tipos de bosques y selvas ribereñas. Además se observaron lianas de Passiflora sp. (pasionaria) y hierbas que crecen en los bordes de lagunas como Cyperus sp. (papiro criollo), que probablemente no fueron usadas como leña y su carbonización puede haber sido ocasional o incidental.

A este contexto doméstico se le suma el hallazgo de restos óseos humanos de más de 15 individuos adultos, adolescentes e infantes de ambos sexos que han sido estudiados por Scabuzzo et al. (e.p.). Estos se encontraban dispuestos en dos sectores del sitio bien 
diferenciados: el núcleo de inhumación en la base del montículo y un fogón discreto en la cima. En el núcleo de inhumación se halló la mayoría de los individuos en un área de 10 $\mathrm{m}^{2}$ que se localiza a $12 \mathrm{~m}$ de las cuadrículas abiertas en la cima del montículo (donde se encuentra el fogón con restos humanos). El núcleo de inhumación está ubicado en la base del montículo que es el sector más afectado por las crecidas del río. Esto último marca una recurrencia regional ya que esta localización se repite en distintos montículos (por ejemplo Torres 1911). La matriz sedimentaria que contenía los esqueletos presentaba espículas de carbón, un gran bloque de pigmento rojo (hematita), abundantes restos cerámicos y de alimentación, entre estos mandíbulas y dientes de coipos y vértebras de peces alteradas por el fuego. A esto se le agregan valvas de Diplodon sp. dispuestas en capas por encima y debajo de los entierros humanos. Aun cuando algunos elementos, como las valvas o fragmentos grandes de vasijas rotas in situ, están claramente asociados con las inhumaciones, otros materiales seguramente formaban parte de los sedimentos donde se enterraron los esqueletos y con los que se los taparon. En efecto, por debajo de la mayor concentración de esqueletos humanos, se registró el basurero mencionado con anterioridad.

En el núcleo de inhumación hubo una manipulación diferencial de los restos esqueletarios que quedó reflejada en elaboradas prácticas mortuorias. Estas prácticas incluyeron entierros primarios, paquetes secundarios y la disposición de partes anatómicas aisladas con tejidos que las mantenían articuladas. De esta manera, los cuerpos estuvieron sujetos a distintos tratamientos y siguieron diferentes trayectorias de entierro, exhumación y re-entierro. Los cuatro fechados radiocarbónicos obtenidos para los restos humanos del núcleo abarcan entre 650 y 850 años AP y son posteriores al inicio de la construcción del cerro en torno a los 1000 AP. La información disponible indica que el montículo primero fue un área residencial y que más tarde comenzó a ser utilizado como espacio funerario.

El segundo sector con restos humanos se ubica en la zona central y más elevada del montículo, donde se hallaron los restos de un único individuo adulto dentro de un fogón. Los huesos humanos fueron datados en 775 años AP y se encontraban altamente fragmentados, pintados de rojo y asociados con restos de fauna termoalterados y tiestos cerámicos. Por el momento, se plantean dos alternativas para explicar este tratamiento diferencial, así como su disposición en un contexto particular y en un lugar distinto con relación a los sucesivos entierros humanos ocurridos por lo menos durante dos siglos. Una posibilidad es que se trate de la cremación de un individuo importante y que estas diferencias respondan a diferencias sociales, mientras que la otra es que se trate de un episodio de canibalismo ritual (véanse discusiones recientes sobre canibalismo en las tierras bajas sudamericanas en Gascue 2009; López Mazz y Moreno 2010; Solari y Duarte do Pateo 2012; entre otros).

\section{Discusión}

Los nuevos datos y la investigación sistemática en las tierras bajas del Cono Sur han permitido situar el origen y desarrollo de las construcciones prehispánicas en tierra como un tema central de debate en la arqueología sudamericana (Bonomo et al. 2011a; Bracco 2006, Iriarte 2006; López Mazz 2001, Politis 2007). Mientras que las investigaciones en Uruguay han generado un corpus empírico muy importante en los últimos 30 años, los estudios sobre las estructuras de tierra en el Delta del Paraná han sido retomados recién en los últimos 5 años (a pesar que en los inicios de la arqueología argentina fue uno de los temas de mayor interés, véase por ejemplo Ameghino 1880; Torres 1911). 
Los resultados obtenidos en ambas regiones muestran diferentes procesos de ocupación humana y transformación del entorno "natural" mediante los cuales se crearon espacios antropizados que han pervivido hasta la actualidad, siendo incluso utilizados por poblaciones actuales. Además, estos procesos tienen cronologías distintas. El fenómeno monticular aparece en el Holoceno medio en el E y NE de Uruguay, en ca. 5000 y 3300 años AP respectivamente, mientras que en los cursos inferiores del Paraná y el Uruguay el proceso parece ser más reciente: $c a$. 1400-1000 años AP. Sin embargo, hay que tener en cuenta la diferente intensidad de las investigaciones en ambas regiones, lo que indudablemente puede estar provocando un sesgo de muestreo. Es posible que los montículos del sur de Entre Ríos sean más antiguos que 1400 AP pero, debido a la escasez de dataciones radiocarbónicas, aún no se han detectado las ocupaciones más tempranas. Lo mismo sucede con el NE de Uruguay (Tacuarembó). Allí las edades más antiguas permiten situar el origen de los primeros montículos en torno al $3300 \mathrm{AP}$; no obstante, el número de cerritos excavados y datados en esta zona es notablemente menor en comparación con los del SE (Rocha). Es probable que con el aumento de los trabajos en el NE la cronología se retrotraiga, aunque algunos autores (Bracco 2006; Iriarte 2006) sostienen que el foco más antiguo de los montículos uruguayos está en el SE, en la zona de India Muerta (Rocha). A partir de la ocupación recurrente de esos espacios a lo largo de un extenso período de tiempo y de las diferentes actividades constructivas identificadas (erección de montículos, construcciones en materiales perecederos, acondicionamiento de espacios, gestión de desechos domésticos, remoción de suelos, entre otras) se constituyó un tipo particular de paisaje arqueológico; un paisaje que en las tierras bajas uruguayas adquirió tempranamente una monumentalidad inédita para la región, incluso contemporánea con la de los primeros templos y aldeas del período Precerámico de la costa del Perú (Pozorski y Pozorski 2008).

Los dos casos de estudio permiten entender la formación de los montículos como un proceso de larga duración, constituido sobre la base de diferentes actividades recurrentes: domésticas, agrícolas, funerarias, constructivas, remodelación, mantenimiento e incluso sustitución de estructuras anteriores por otras nuevas. La presencia de rupturas dentro de esta dinámica, señaladas por picos de ocupaciones y crecimiento acrecional, actividad constructiva, seguidas por fases pasivas o de abandono, deja entrever un desarrollo que no es lineal. El análisis estratigráfico junto con las dataciones absolutas muestran a la formación de los montículos como un proceso con discontinuidades, pero al mismo tiempo continuo; algo que ya fue reconocido como un "ritmo cultural" inherente al propio fenómeno (Criado Boado et al. 2005). Esto mismo puede ser extrapolado a la escala del paisaje; los cerritos pueden configurar un paisaje monumental en el que la monumentalización debe ser entendida como un largo proceso, a través del cual ciertos espacios, y casi siempre los mismos, son construidos, mantenidos y reconstruidos por siglos o milenios. Es así que los cerritos estudiados del Delta del Paraná y del NE de Uruguay no son el producto de eventos únicos de construcción, sino la sumatoria de procesos constructivos y acrecionales diacrónicos y sincrónicos.

Por otra parte, ambos casos estudiados permiten entender cómo la construcción de estructuras en tierra se ha visto sustentada por la consolidación de economías mixtas que parecen haber sido parte de la clave del éxito adaptativo en estos ambientes húmedos con abundantes recursos acuáticos. Los montículos aparecen dentro del paisaje arqueológico como nodos de vida, no solo situados estratégicamente para aprovechar de forma complementaria diferentes plantas y animales a lo largo del año, sino incluso funcionando como espacios propicios para huertos que incluían los cultivos del complejo maíz-porotozapallo. En qué grado la alimentación de estas poblaciones dependió de los recursos silvestres 
y de los cultivos es un problema de discusión actual, que quizás no encuentre una única respuesta. Lo cierto es que, el esfuerzo por mantener una economía mixta y no depender de unos pocos recursos puede entenderse precisamente como estrategia exitosa, tanto desde un punto de vista adaptativo como social, para reproducir un orden social propio de las sociedades sin Estado (sensu Clastres 1978).

Tradicionalmente, los guaraníes de origen amazónico fueron considerados los representantes del "neolítico" que unos pocos siglos antes de la Conquista introdujeron los cultivos en las poblaciones locales de las dos regiones analizadas en este artículo (véase Bonomo et al. 2011b; Iriarte 2006), estableciéndose así una falsa dicotomía entre cazadoresrecolectores originarios y horticultores foráneos. Como se ha señalado, en las tierras bajas uruguayas las plantas domesticadas estaban integradas en una economía mixta varios milenios antes del arribo de los guaraníes. Si bien con edades más tardías (970-1030 años AP), en Los Tres Cerros 1 también existen registros de maíz para cuando los guaraníes se encontraban a más de 900 km aguas arriba por el río Paraná (Bonomo y Angrizani 2012).

Analizada desde una perspectiva ecológica e histórica (Erickson 2006), la arquitectura en tierra sudamericana constituye, junto a otras actividades (desbroce, trasplante de plantas, fertilización, siembra, manejo del fuego), una tecnología, un saber-hacer que provocó niveles de transformación óptimos para la generación y conservación de los recursos silvestres. De esta manera, muchos de los que tradicionalmente se han asumido como ecosistemas naturales están más cercanos a un paisaje culturalmente creado y modificado en el largo plazo (Erickson 2006; Heckenberger et al. 2003). En este contexto, también la construcción de montículos es entendida como parte de un sistema social de manejo ecológico del medio. Es por ello que cualquier aproximación al estudio de los paisajes arqueológicos de las tierras bajas debiera integrar el rol que jugó, entre las poblaciones prehispánicas, el desarrollo de la arquitectura en tierra como dispositivo social de transformación de la naturaleza.

Asimismo, los "cerritos" de Uruguay y del Delta del Paraná, en su carácter de construcciones antrópicas permanentes, son elementos arquitectónicos, visibles y eminentemente espaciales y temporales. Constituyen lugares que han sido humanizados durante centurias mediante formas materiales que ordenaron el asentamiento humano y estructuraron la movilidad y la interacción social. Son también tecnologías de producción social que seguramente actuaron como base en los procesos de enculturación, definición y producción de individuos (Bourdieu 1977) y, por ende, de grupos sociales. Una tecnología social que se complejiza cuando estas construcciones comienzan a ser destinadas para el entierro de los difuntos y pasan a funcionar como nexos temporales entre el pasado y presente de las comunidades que los utilizan.

La recurrencia de las ocupaciones humanas en los mismos lugares y el uso doméstico reiterado de los montículos, junto a la actividad constructiva durante períodos prolongados, es el factor desencadenante a la hora de reconocer los patrones de asentamiento en ambas regiones. En el SE y NE de Uruguay, los sitios monticulares funcionaron como aldeas vinculadas entre sí, dentro de un territorio más amplio. La densidad de sitios monticulares en las planicies de inundación de los arroyos Yaguarí y Caraguatá evidencia el poblamiento efectivo de las tierras bajas del NE con una densidad demográfica importante para ese período de la prehistoria. En el Delta existió una red de sitios con diferente función, jerarquía e intensidad de ocupación, aunque los cerros exhiben agrupaciones menores que parecen 
haber actuado como espacios, en algunos casos pequeñas aldeas, que albergaron familias o grupos de ellas posiblemente emparentadas. Algo similar a lo que se ha descrito para los guató del Pantanal (Eremites de Oliveira 1995). A su vez, como se ha señalado previamente, las dataciones de ambas regiones muestran cierta continuidad en la ocupación de los montículos dentro de una misma localidad, en la que también se constata algún período corto de inactividad. Esto permite proponer el funcionamiento de las estructuras monticulares como asentamientos residenciales semipermanentes.

La interacción con otros grupos (e.g. guaraníes) dentro del mismo territorio o bien de áreas vecinas parece estar documentado no solo en las primeras crónicas de ambas regiones, sino por la presencia de objetos foráneos dentro de los montículos. En el caso de los cerritos uruguayos, el registro de algunos objetos exóticos como zoolitos podría estar indicando contactos a larga distancia con poblaciones del litoral atlántico brasileño (Andrade y López Mazz 1999). Los entierros en urnas guaraníes dentro de algunos montículos abren el debate acerca de las distintas modalidades de interacción (que no siempre fueron conflictivas) y sobre la apropiación simbólica del paisaje por medio del uso funerario de estas construcciones por parte de guaraníes (Cabrera 2005). En el Delta Superior del Paraná ocurre algo semejante. Se ha detectado un entierro en una urna polícroma, tres recipientes completos y un número reducido de tiestos corrugados y unguiculados en las capas superiores o la superficie de ocho sitios (cerritos y albardones). Estos objetos parecen ser el fruto de la circulación de bienes y personas a distancias considerables de los asentamientos guaraníes identificados en el Delta Inferior.

\section{Consideraciones finales}

A través de las investigaciones arqueológicas en las regiones del Delta del Paraná y del noreste de Uruguay se ha aportado información relevante para la comprensión de los procesos evolutivos y las trayectorias históricas de las poblaciones indígenas de las tierras bajas del Cono Sur americano. Los montículos deltaicos y los cerritos uruguayos constituyen paisajes arqueológicos particulares que permiten entender las lógicas socioeconómicas y simbólicas detrás de la construcción de territorios sociales en torno a las tierras bajas. En ambos escenarios, la construcción de montículos surge como una tecnología social que permitió la adaptación, utilización y transformación de estos ecosistemas húmedos en espacios antropizados. Asistimos a un proceso que podríamos describir como culturización de la naturaleza y que se manifiesta a través de las diferentes prácticas asociadas a la construcción y uso de estos montículos. Estas prácticas forman parte de un sistema que facilitó la explotación del medio, mediante actividades extractivas, productivas y otras que permitieron mejorar la biodiversidad. En este entramado, los montículos fueron el dispositivo empleado para consolidar la organización y apropiación social del espacio y el manejo cultural de la naturaleza.

Este proceso se advierte en otros ámbitos; los habitantes de los cerritos crearon espacios antropizados, reutilizando rasgos naturales que son integrados y maximizados dentro del orden doméstico, no solo con la propia construcción, sino también mediante la preparación de suelos para el cultivo, el aprovechamiento de pequeñas lagunas naturales dentro de los sitios y el mantenimiento de espacios de gran biodiversidad. Algo similar a lo que sucedió en el Delta, donde además la incorporación del mundo animal en el estilo cerámico (la entidad arqueológica Goya-Malabrigo) es un elemento más que permite discutir la relación naturaleza-cultura. 
En términos más amplios, este proceso se reconoce también en la economía utilizada por los habitantes de ambas regiones, en donde el mantenimiento de estrategias basadas en el aprovechamiento de recursos silvestres $y$, en menor medida, de especies vegetales domesticadas permitió ampliar la dieta. Las prácticas de producción de alimentos, muestran economías locales con un componente hortícola orientado al cultivo del difundido complejo de cultivos tropicales: maíz-poroto-zapallo.

El origen y la formación de los sitios monticulares, tanto en el Delta del Paraná como en el noreste uruguayo, parecen tener trayectorias históricas diferentes (véase Andrade y Lopez Mazz 1999; Politis y Bonomo 2012). Mientras que en el noreste y sureste de Uruguay se han detectado procesos relativamente largos de génesis de estas modalidades sociales, incluso precedidas en algunos casos por ocupaciones pre-cerritos de cazadores-recolectores sin cerámica (Iriarte 2006; López Mazz 2001), en el Delta del Paraná, la aparición de los cerritos es más reciente, más abrupta y parece tener una génesis alóctona. En este sentido, se ha planteado que su origen podría estar vinculado a la expansión meridional del grupo etno-lingüístico arawak (Nordenskiöld 1916; Politis y Bonomo 2012). Sin embargo, en los dos casos de estudio se reconocen procesos en los cuales los pobladores que habitaron los cerritos, a través del uso, modificación y mantenimiento de la arquitectura en tierra, fueron otorgando y acumulando significados en ciertos lugares. Estos terminaron constituyéndose en espacios de memoria y nodos territoriales, es decir puntos que articulan y conforman el territorio social y que están configurados por la localización recurrente de asentamientos en lugares estratégicos. En este proceso, la transformación del cerrito también en un espacio funerario seguramente dio lugar al establecimiento de una relación histórica con el territorio. Los cerritos pasaron a ser estructuras de larga duración que habrían conectado pasado y presente a través de los ancestros y los vivos, y al mismo tiempo se proyectarían hacia el futuro como lugares de memoria (véase propuestas similares para otras regiones en Brown 1995; Buikstra y Charles 1999; Dillehay 1995). Esta dinámica, analizada a partir de su principal componente material (los montículos), es la que permite reconocerla como un tipo específico de paisaje arqueológico de las tierras bajas sudamericanas.

Agradecimientos: A Sebastián Pastor por su invitación (y paciencia) a formar parte de este dossier sobre arqueología del paisaje. A Gustavo Politis por sus generosos y valiosos comentarios que ayudaron a mejorar este artículo del cual lo consideramos su co-autor. Este trabajo se desarrolló gracias al proyecto de cooperación científica entre el Incipit (CSIC) y el LAPPU (FHCE-CURE, Universidad de la República): “El paisaje arqueológico de las tierras bajas uruguayas", dirigido por Camila Gianotti y Felipe Criado y financiado por la Dir. General de Bellas Artes del Ministerio de Cultura de España. Los actuales estudios comparados entre la región del Delta del Paraná y las tierras bajas uruguayas se enmarcan en los proyectos: Paisajes del Movimiento, financiado por la Agencia Nacional de Investigación e Innovación (FCE_2_2011_1_5679) dirigido por Camila Gianotti y "Las estructuras monticulares del Delta Superior del Paraná"(PICT 0665) dirigido por Mariano Bonomo. Los únicos responsables de los contenidos del trabajo son los autores.

\section{Notas}

1La información paleoambiental para la región centro-este del país es escasa. Los datos generados en nuestras investigaciones permiten reconocer variaciones en la temperatura, precipitaciones y distribución de cobertura vegetal que no afectaría, en términos generales, al reconocimiento del patrón de localización de sitios con montículos y su relación con las diferentes unidades ambientales al menos para los últimos 3000-2500 años A.P. 
2 La topografía del área está caracterizada por Cuchillas que funcionan como las divisorias de aguas de las cuencas de los principales arroyos (Cuchilla del Yaguarí, Cuchilla del Hospital, Cuchilla de Pereira) y sus dorsales de estribación que discurren transversales a los ríos. Éstas últimas son lomadas de relieve suave, con cobertura vegetal de gramíneas.

\section{Bibliografía citada}

Alexiades, M.N.

2009 Mobility and Migration in Indigenous Amazonia: Contemporary Ethnoecological Perspectives - an Introduction. Berghahn Books: 1-43, New York.

Ameghino, F.

1880 La antigüedad del hombre en el Plata. Masson, Paris-Buenos Aires.

Andrade Lima, T. y J. López Mazz

1999 La emergencia de la complejidad entre los cazadores recolectores de la costa Atlántica meridional sudamericana. Revista de Antropología Americana 17,18,19: 129-175.

Baeza J., A. Díaz, R.W. Melgar, A. Caimi, C. Etcheverry, J. Barone, S.L. Lucas, C. Gereda, A. Borcha y E. Barboza

1974 Informe preliminar sobre los cerritos en la zona de Cañada de Las Pajas. V Congreso Nacional de Arqueología, Colonia.

Balée W. y C. Erikson

2006 Time and Complexity in Historical Ecology. Studies in Neotropical Lowlands. Columbia University Press. New York

Barreto, C.

2006 Caminos a la desigualdad: perspectivas desde las Tierras bajas de Brasil. Contra la tiranía tipológica en Arqueología. Una visión desde Sudamerica (ed. por C. Gnecco, C.H.Langebaek y C. Henrik), pp. 5-32. Aldine, Chicago.

Bastourre, M.L.

2012 Estudios arqueofaunísticos en el Delta Superior del Paraná: el sitio Los Tres Cerros 1. Trabajo presentado en el II Encuentro Latinoamericano de Zooarqueología. Departamento de Antropología de la Facultad de Ciencias Sociales, Universidad de Chile, Santiago de Chile.

Bonomo, M. y R. Angrizani

2012 El espacio en el tiempo. La expansión meridional de los guaraníes en la cuenca del Plata durante el Holoceno tardío. Trabajo presentado en la VI Reunión de Teoría Arqueológica en América del Sur. PUC-Goias, Goiània, Brasil.

Bonomo M., G. Politis y J. C. Castro

2010 Primeros resultados de las investigaciones arqueológicas en el Delta Superior del Paraná y su contribución al atlas arqueológico de la provincia de Entre Ríos. Folia Histórica del Nordeste 18: 33-58. 
Bonomo M., G. Politis y C. Gianotti

2011a Montículos, jerarquía social y horticultura en las sociedades indígenas del Delta del río Paraná (Argentina). Latin American Antiquity 22(3): 297-333.

Bonomo, M., J. Aceituno Bocanegra, G. Politis y M. L. Pochettino

2011b Pre- hispanic horticulture in the Paraná Delta (Argentina): Archaeological and historical evidence. World Archaeology 43(4): 557-579.

Bracco, R.

2006 Montículos de la Cuenca de la Laguna Merín: Tiempo, Espacio y Sociedad. Latin American Antiquity 17: 551-540.

Bracco, R, L. Cabrera y J. López Mazz

2000 La Prehistoria de las Tierras Bajas de la Cuenca de la Laguna Merín. Arqueología de las Tierras bajas (ed. por A. Durán y R. Bracco), pp. 13-38. MEC, Montevideo.

Brea, M., M. J. Franco, M. Bonomo y G. Politis

2013 Análisis antracológico preliminar del sitio arqueológico Los Tres Cerros 1 (Delta Superior del río Paraná). En prensa en Revista del Museo de La Plata 13(87).

Brown, J.

1995 On Mortuary Analysis with Special Reference to the Saxe-Binford Research Program. Regional Approaches to Mortuary Analysis (ed. por L. Beck), pp. 3-26. Plenum Press, Nueva York.

Buikstra, J. y D. Charles

1999 Centering the ancestors: Cemeteries, mounds, and sacred landscapes of the ancient North American Midcontinent. Archaeologies of Landscape (ed. por W. Ashmore y A. Knapp), pp. 202-228. Blackwell, Cambridge.

Cabrera, L.

2005 Patrimonio y Arqueología en el Sur de Brasil y región Este del Uruguay: los cerritos de indios. Saldvie 5: 221-254.

\section{Cabrera L. y O. Marozzi}

2001 Las áreas domésticas de los constructores de cerritos: el sitio CG14EO1. En Arqueología uruguaya hacia el fin del milenio. IX Congreso de Arqueología Uruguaya (ed. por Ministerio de Cultura), pp. 55-68. Gráficos del Sur, Montevideo.

Capdepont, I., L. del Puerto y H. Inda.

2002 Caracterización tecnológica y funcional del material cerámico arqueológico de la Cuenca de la Laguna de Castillos. Del mar a los salitrales. Diez mil años de historia Pampeana en el umbral del tercer milenio (ed. por D. Mazzanti, M. Berón y F. Oliva.), pp. 41-50. Universidad Nacional de Mar del Plata, Mar del Plata.

Capdepont, I., L. del Puerto y H. Inda

2005 Análisis de sedimentos de la estructura monticular YALE27 y su entorno. Cooperación científica, desarrollo metodológico y nuevas tecnologías para la gestión integral del Patrimonio arqueológico en Uruguay (coord. por C. Gianotti), TAPA 36, pp. 99-108. IEGPS (CSIC), Santiago de Compostela. 
Carden, N.

2009. Imágenes a través del tiempo. Arte rupestre y construcción social del paisaje en la Meseta Central de Santa Cruz. Sociedad Argentina de Antropología, Buenos Aires.

Castiñeira C., A. Blasi, G. Politis, M. Bonomo, L. del Puerto, R. Huarte, J. Carbonari, F. Mari y F. García Rodríguez

2013 The Origin and Construction of Pre-Hispanic Mounds in the Upper Delta of the Paraná River (Argentina). Archaeological and Anthropological Sciences 5(1): 37-57.

Castro, J. C.

2012 Arqueología en la cuenca del río Uruguay (Provincia de Entre Ríos). Cazadores Recolectores del Cono Sur 5: 135-162.

Ceruti, C.

1993 Arqueología. Nueva Enciclopedia de la Provincia de Santa Fe (ed. por A.D. Renna), tomo IV, pp. 557-580. Ediciones Sudamérica, Santa Fe.

Ceruti, C. y M. I. González

2007 Modos de vida vinculados con ambientes acuáticos del Nordeste y Pampa bonaerense de Argentina. Relaciones de la Sociedad Argentina de Antropología 32: 101-140.

Clastres, P.

1978 [1974] La Sociedad contra el Estado. Monte Ávila, Barcelona.

Copê, S.

1991 A ocupacao pré-colonial do sul e sudeste do Rio Grande do Sul. Arqueología Prehistórica de Rio Grande do Sul (ed. por A. Kern), pp. 191-220. Mercado Aberto, Porto Alegre

Criado Boado, $\mathrm{F}$.

1991 Construcción social del espacio y reconstrucción arqueológica del paisaje. Boletín de Antropología Americana 24: 7-29.

1993 Límites y posibilidades de la arqueología del paisaje. Spal 2: 9-55.

Criado Boado, F., J.M. López Mazz y C. Gianotti

2004 Arqueología en el Valle del Arroyo Yaguarí. Diseño de Proyecto y primeras actividades. Trabajo presentado en el X Congreso de Arqueología uruguaya. Noviembre 2001 (en CD-ROM).

Criado Boado, F., C. Gianotti y P. Mañana-Borrazás

2005 Before the barrows: forms of monumentality and forms of complexity in Iberia and Uruguay. Archaeology of Burial Mounds (ed. por L. Smejda), pp. 38-52. University of West Bohemia, Czech Republic.

Curbelo, C., R. Bracco, L. Cabrera, J. Femenías, N. Fusco, J. López Mazz y E. Martínez 1990 Estructuras de sitio y zonas de actividad: sitio CH2D01, área de San Miguel, Departamento de Rocha, ROU. Revista do Cepa 17 (20): 333-344.

Curtoni, R.

2007 Arqueología y paisaje en el área centro-este de la provincia de La Pampa: la espacialidad humana y la formación de territorios. Tesis de Doctorado. Universidad Nacional de La Plata. La Plata. 
Daniels, S. y D.E. Cosgrove

1988 Introduction: iconography and landscape. The Iconography of Landscape. Essays on the Symbolic Representation, Design and Use of Past Environments (ed. por D.E. Cosgrove y S. Daniels), pp. 1-10. Cambridge University Press, Cambridge.

David, B. y J. Thomas (eds.)

2010 Handbook of Landscape Archaeology. World Archaeological Congress. Left Cost Press. California

de Blasis, P., A. Kneip, R. Scheel-Ybert., P. César Giannini y M.D. Gaspar

2007 Sambaquies e paisagem. Dinâmica natural e arqueología regional no litoral do Sul do Brasil. Arqueología Suramericana 3(1): 29-61

del Puerto, L.

2003 Paleoetnobotánica y subsistencia: ponderación de recursos vegetales y análisis arqueobotánico para el Este del Uruguay. Tesis de Licenciatura. Universidad de la República, Montevideo. 2009 Análisis de partículas biosíliceas del sito Pago Lindo, Departamento de Tacuarembó (Uruguay). Paisaje monumental de las tierras bajas uruguayas (ed. por C. Gianotti). Memoria técnica. Proyecto de cooperación científica "El paisaje arqueológico de las tierras bajas uruguayas". Inédito. DGBC, Ministerio de Cultura, Madrid.

del Puerto, L. y H. Inda

2005 Paleoetnobotánica de los constructores de túmulos del Noreste del Uruguay: Análisis de silicofitolitos de la estructura monticular YALE 27 y su entorno. Proyecto de cooperación científica: desarrollo metodológico y aplicación de nuevas tecnologías para la gestión del patrimonio arqueológico en Uruguay (coord. por C. Gianotti), TAPA 36, pp. 109-120. IEGPSCSIC, Santiago de Compostela.

Di Prado, V. y C. Castro

2013 Estrategia de remontajes aplicada sobre el registro cerámico del sitio Los Tres Cerros 1 (Delta Superior del Paraná). Trabajo presentado en el XVIII Congreso Nacional de Arqueología Argentina, La Rioja.

Dillehay, $\mathrm{T}$.

1995 Mounds of Social Death: Araucanian Funerary Rites and Political Succession. Tombs for the Living: Andean Mortuary Practices (ed. por T. Dillehay), pp. 281-314. Dumbarton Oaks, Washington.

Edmonds, M.

1999 Ancestral Geographies of the Neolithic. Routledge, Londres.

Endere, M.L. y R. Curtoni

2003 Patrimonio, arqueología y participación: acerca de la noción de paisaje arqueológico. Análisis, Interpretación y Gestión en la Arqueología de Sudamérica (ed por R. Curtoni y M.L. Endere), pp. 277-296. Serie Teórica 2, INCUAPA, UNICEN. Olavarría.

Eremites de Oliveira, J.

1995 Os Argonautas Guató: aportes para o conhecimento dos assentamentos e da subsistência dos grupos que se estabeleceram nas áreas inundáveis do Pantanal Matogrossense. Tesis de Maestría. PUCRGS, Porto Alegre. 
Erickson, C.

2006 The Domesticated Landscapes of the Bolivian Amazon. Time and Complexity in Historical Ecology: Studies in the Neotropical Lowlands (ed. por W. Balée y C. Erickson), pp. 235-278. Columbia University Press, New York.

2009 Agency, Causeways, Canals, and the Landscapes of Everyday Life in the Bolivian Amazon. Landscapes of Movement. Trails, Paths, and Roads in Anthropological Perspective (ed. por J. Snead, C. Erickson y A. Darling), pp. 204-231. University of Pennsylvania Press, Philadelphia.

Escobar, A.

2001 Culture sits in places: reflections on globalism and subaltern strategies of localization. Political Geography 20: 129-174.

Fleming A.

2006 Post-processual Landscape Archaeology: a Critique. Cambridge Archaeological Journal 16(3) 267-80.

Gascue, A.

2009 Prácticas violentas entre los habitantes prehistóricos de la Cuenca del Plata: la evidencia arqueológica de los valles de los ríos Paraná y Uruguay. La arqueología como profesión: los primeros 30 años. XI Congreso Nacional de Arqueología Uruguaya (L. Beovide, C. Erchini y G. Figueiro), pp. 392-407. Asociación Uruguaya de Arqueología, Montevideo.

Gianotti, C.

2000 Paisajes monumentales en la región meridional sudamericana. Gallaecia 19: 43-72. 2004 La prospección como estrategia metodológica para el estudio del paisaje monumental en las tierras bajas uruguayas. Arqueología Espacial SAET 24-25: 259-282.

2005 Intervenciones arqueológicas en el cerrito 27 del Conjunto Lemos. Desarrollo metodológico y aplicación de nuevas tecnologías para la gestión integral del Patrimonio Arqueológico en Uruguay (coord. por C. Gianotti), pp. 79-98. TAPA 36, IEGPS (CSIC), Santiago de Compostela.

Gianotti, C., L. del Puerto L., H. Inda e I. Capdepont

En prensa. Construir para producir. Pequeñas elevaciones en tierra para el cultivo de maíz en el sitio Cañada de los Caponcitos, Tacuarembó(Uruguay). Revista Cuadernos del INAPL. Buenos Aires.

Gianotti, C., F. Criado Boado, G. Piñeiro, N. Gazzán, I. Capdepont, Y. Seoane y C. Cancela 2009 Dinámica constructiva y formación de un asentamiento monumental en el Valle de Caraguatá, Tacuarembó. Excavaciones en el exterior 2008. Informes y Trabajos, pp. 245-254. IPCE, MCU, Madrid.

Gianotti, C., F. Criado Boado y J. López-Mazz

2008. Arqueología del Paisaje: la construcción de cerritos en Uruguay. Excavaciones en el exterior 2007. Informes y Trabajos, Pp. 177-185. IPCE, MCU, Madrid.

Gianotti, C. y E. Leoz

2001 Hacia una arqueología del movimiento en la cuenca del arroyo Yaguarí, Tacuarembó, R.O.U. Arqueología uruguaya hacia el fin del milenio. IX Congreso de Arqueología Uruguaya (ed. por MEC-AUA), pp. 135-146. Gráficos del Sur, Montevideo. 
Godelier, M.

1989 Lo ideal y lo material: pensamiento, economías, sociedades. Taurus, Madrid.

Heckenberger, M. y E.G. Neves

2009 Amazonian Archaeology. Annual Review of Anthropology 38: 251-66.

Heckenberger, M., A. Kuikuro, U. T. Kuikuro, C. Russell, M. Schmidt, C. Fausto y B. Franchetto 2003 Amazonia 1492: Pristine forest or Cultural Packland? Science 301:1710-1713.

Inda, $\mathrm{H}$.

2005 Análisis antracológico de los restos de carbón procedentes del Cerrito 27, Sitio Lemos, Arroyo Yaguarí. Paisaje monumental de las tierras bajas uruguayas (coord. por C. Gianotti). Memoria técnica. Proyecto de cooperación científica "El paisaje arqueológico de las tierras bajas uruguayas". Inédito. DGBC, Ministerio de Cultura, Madrid.

Ingold, $\mathrm{T}$.

1993 The temporality of the landscape. World Archaeology 25 (2): 152-174.

1997 The picture is not the terrain. Maps, paintings and the dwelt-in world. Archaeological Dialogues 4 (1): 29-31.

Iriarte, $\mathrm{J}$.

2006 Landscape Transformation, Mounded Villages and Adopted Cultigens: The Rise of Early Formative Communities in South-Eastern Uruguay. World Archaeology 38:644-663.

Johnson, $\mathrm{M}$.

2008 Ideas of Landscape. Blackwell Publishing, Oxford.

Lombardo, U. y H. Prümers

2010 Pre-Columbian human occupation patterns in the eastern plains of the Llanos de Moxos, Bolivian Amazonia. Journal of Archaeological Science 37(8): 1875-1885.

López Mazz, J. M.

1998 Desarrollo de la Arqueología del Paisaje en Uruguay. El caso de la Tierras Bajas de la Cuenca de la Laguna Merín. Arqueología Espacial SAET 19-20: 633-647.

2001 Las estructuras tumulares (cerritos) del Litoral Atlántico uruguayo. Latin American Antiquity 12: 1-25.

López Mazz, J.M. y Gascue A.

2005 Aspectos de las tecnologías líticas desarrolladas por los grupos constructores de cerritos del Arroyo. Cooperación científica, desarrollo metodológico y nuevas tecnologías para la gestión integral del Patrimonio arqueológico en Uruguay (coord. por C. Gianotti), TAPA 36, pp. 123-145. IEGPS (CSIC), Santiago de Compostela.

López Mazz, J.M. y S. Pintos

2001 El paisaje arqueológico de la Laguna Negra. Arqueología uruguaya hacia el fin del milenio. IX Congreso de Arqueología Uruguaya, pp. 175-186. MEC, Gráficos del Sur, Montevideo.

López Mazz, J. M. y C. Gianotti

1998 Construcción de espacios ceremoniales públicos entre los pobladores de las tierras bajas de Uruguay. Revista de Arqueología 11: 87-105. 
López Mazz, J.M. y R. Bracco

1994 Cazadores-Recolectores de la Cuenca de la Laguna Merín: Aproximaciones teóricas y modelos arqueológicos. Arqueología de Cazadores-Recolectores. Límites, Casos y Aperturas (ed. por J.L. Lanata y L.A. Borrero), pp. 51-64. Arqueología Contemporánea, Buenos Aires.

López Mazz, J.M. y F. Moreno

2010 El cambio social en la prehistoria de las Tierras Bajas del este de Uruguay: la visibilidad arqueológica del conflicto. Arqueología Argentina en el Bicentenario de la Revolución de Mayo. Actas del XVII Congreso Nacional de Arqueología Argentina (ed. por J. R. Bárcena y H. Chiavazza), pp. 943-948. UNCuyo, Mendoza.

Mazzia, N.

2011 Lugares y paisajes de cazadores recolectores en la pampa bonaerense: cambios y continuidades durante el Pleistoceno final- Holoceno. Tesis de Doctorado. Universidad Nacional de La Plata, La Plata.

Naue, G., P. Schmitz, W. Valente e I. Becker

1971 Novas perspectivas sobre a arqueologia de Rio Grande do sul. O homen Antigo na America (Instituto de Prehistoria, USP editor), pp. 99-122. São Paulo.

Nordenskiöld, E.

2009 [1916] Indian Adaptations in Flooded Regions of South America (Introduction Denevan, W.). Journal of Latin American Geography 8(2): 209-224.

Piazzini, C.E.

2006 Arqueología, espacio y tiempo: una mirada desde Latinoamérica. Arqueología Suramericana 2(1): 3-25.

Pintos, S.

1999 Túmulos, caciques y otras historias. Cazadores recolectores complejos en la Cuenca de la Laguna de Castillos, Uruguay. Complutum 10: 213-226.

Politis, G.

2007 Nukak: Ethnoarchaeology of an Amazonian People. Walnut Creek, Left Coast.

Politis, G. y M. Bonomo

2012 La entidad arqueológica Goya-Malabrigo (Ríos Paraná y Uruguay) y su filiación Arawak. Boletín de la $S A B$, en prensa.

Politis, G., M. Bonomo, C. Castiñeira y A. Blasi

2011 Archaeology of the Upper Delta of the Paraná River (Argentina): mound construction and anthropic landscapes in the Los Tres Cerros locality. Quaternary International 245(1): 74-88.

Politis, G., M. Bonomo y V. Di Prado

2013 Ceramistas de la ribera. Los antiguos pobladores del delta del Paraná. Ciencia Hoy 23(133): 31-77.

Posey, D.

2002 Indigenous management of tropical forest ecosystems: the case of the Kayapó Indians of the Brazilian Amazon (1985). Kayapó: Ethnoecology and Culture (ed. por K. Plenderleith), pp. 200-216. Routledge, New York. 
Pozorski S. y T. Pozorski

2008 Early Cultural Complexity on the Coast of Perú. Handbook of South American Archaeology (ed. por H. Silverman y W. Isbell), pp. 607-631. Springer, New York.

Rossignol, J. y L. Wandsnider

1992 Space, Time and Archaeological Landscapes. Plenum Press, New York

Rostain, S.

2012a Islands in the Rainforest Landscape Management in Pre-Columbian Amazonia. Left Coast Press, Walnut Creek.

2012b Upano Precolombino. IPGH, Quito.

Ruíz, A., M. Molinos y C. Rísquez.

1998 Paisaje y Territorio mundo: dos dimensiones de una misma teoría arqueológica. Arqueología Espacial 19-20: 21-32.

Rüthschilling, A.

1989 Pesquisas arqueológicas no baixo rio Camaquã. Documentos 3: 7-106. São Leopoldo.

Sánchez, J., M. Colobig y A. Zucol

2011 Análisis fitolíticos del sitio Los Tres Cerros 1, Isla las Moras (Victoria, Entre Ríos). Primeros resultados. Libro de Resúmenes del VI Congreso de Arqueología de la Región Pampeana, p. 123. La Plata.

Sans, M.

1985 Arqueología de la región de Yaguarí (Dpto. de Tacuarembó). En Estado de las Investigaciones arqueológicas en el Uruguay, CEA No 3: 57-61. Montevideo.

Scabuzzo, C., A. Ramos Van Raap, M. Bonomo y G. Politis.

e.p. Complejidad mortuoria en el delta superior del rio Paraná. El sitio los Tres Cerros 1 (departamento de Victoria, Entre Ríos, Argentina). Estados prehispánicos y poblamiento inicial (ed. por J. Marcos y T. Hidrovo). Proyecto Patrimonial: Hojas-Jaboncillos, Montecristi, Ecuador.

Schaan, D.

2012 Sacred Geographies of Ancient Amazonia: Historical Ecology of Social Complexity. New Frontiers in Historical Ecology 3. Left Coast Press, Walnut Creek.

Schmitz, P.I.

1976 Sitios de pesca lacustre em Rio Grande, R. S. Brasil. Inst. Anchietano de Pesquisas, Sao Leopoldo.

Serrano, A.

1950 Los primitivos habitantes de Entre Ríos. Biblioteca Entrerriana "General Perón", Ministerio de Educación, Provincia de Entre Ríos, Paraná, Argentina.

Solari, A. y R. Duarte do Pateo

2012 Arqueología, antropología social y biológica: miradas complementarias para una mejor interpretación del canibalismo humano. Trabajo presentado en la VI Reunión de Teoría Arqueológica en América del Sur. PUC-Goias, Goiània, Brasil. 
Soler Segura, J.

2007 Redefiniendo el registro material. Implicaciones recientes desde la Arqueología del Paisaje anglosajona. Trabajos de Prehistoria 64(1): 41-64.

Suárez, X.

2006 Existió la monumentalidad en tierra entre los cazadores-recolectores del este uruguayo? Propuesta metodológica para el estudio de construcciones antrópicas en tierra. Arqueología Suramericana 2(2): 263-290.

Suárez Villagrán, X. y C. Gianotti

2013 Earthen mound formation in the Uruguayan lowlands (South America): micromorphological analyses of the Pago Lindo archaeological complex. Journal of Archaeological Science 40(2): 1093-1107.

Tilley, C.

1994 A Phenomenology of Landscape. Berg, Oxford.

Thomas, J.

2002 Archaeologies of Place and Landscape. Archaeological Theory Today (ed. por I. Hodder), pp. 165-186. Policy Press, Cambridge.

Torres, L.

1911 Los Primitivos Habitantes del Delta del Paraná. Biblioteca Centenaria, Universidad Nacional de La Plata, Buenos Aires.

Troncoso A.

2008 Arte Rupestre en la Cuenca del Río Aconcagua: Formas, Sintaxis, Estilo y Poder. Serie TAPA N³9, Incipit (CSIC), Santiago de Compostela.

Tuan, Y.F.

2007 [1974] Topofilia. Un estudio de las percepciones, actitudes y valores sobre el entorno. Melusina, Barcelona.

Villarmarzo, E.

2009 Informe del análisis cerámico del sitio Pago Lindo, Tacuarembó (Uruguay). Paisaje monumental de las tierras bajas uruguayas (coord. por C. Gianotti). Memoria técnica. Proyecto de cooperación científica "El paisaje arqueológico de las tierras bajas uruguayas". Inédito. DGBC, Ministerio de Cultura, Madrid.

Walker, J.

2008 The Llanos de Mojos. Handbook of South American Archaeology (ed. por H. Silverman y W. Isbell), pp. 927-940. Springer, New York.

Wüst, I., y C. Barreto

1999 The rings villages of central Brazil: A challenge for Amazonian Archaeology. Latin American Antiquity 10(1): 1-21. 
